Universidad de Lima

Facultad de Comunicación

Carrera de Comunicación

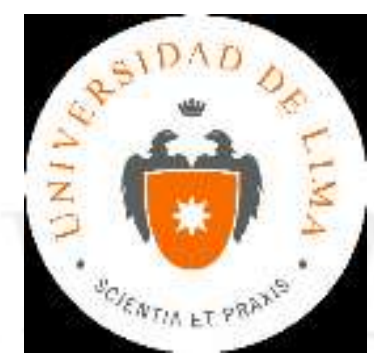

\title{
CAMPAÑA DE LANZAMIENTO DE LA CERVEZA SIN ALCOHOL LEICHT CERO
}

Trabajo de Suficiencia Profesional para optar el Título Profesional de Licenciado en Comunicación

Adriana Elba Angulo Villar

Código 20121473

Lima - Perú

$18-09-2018$ 


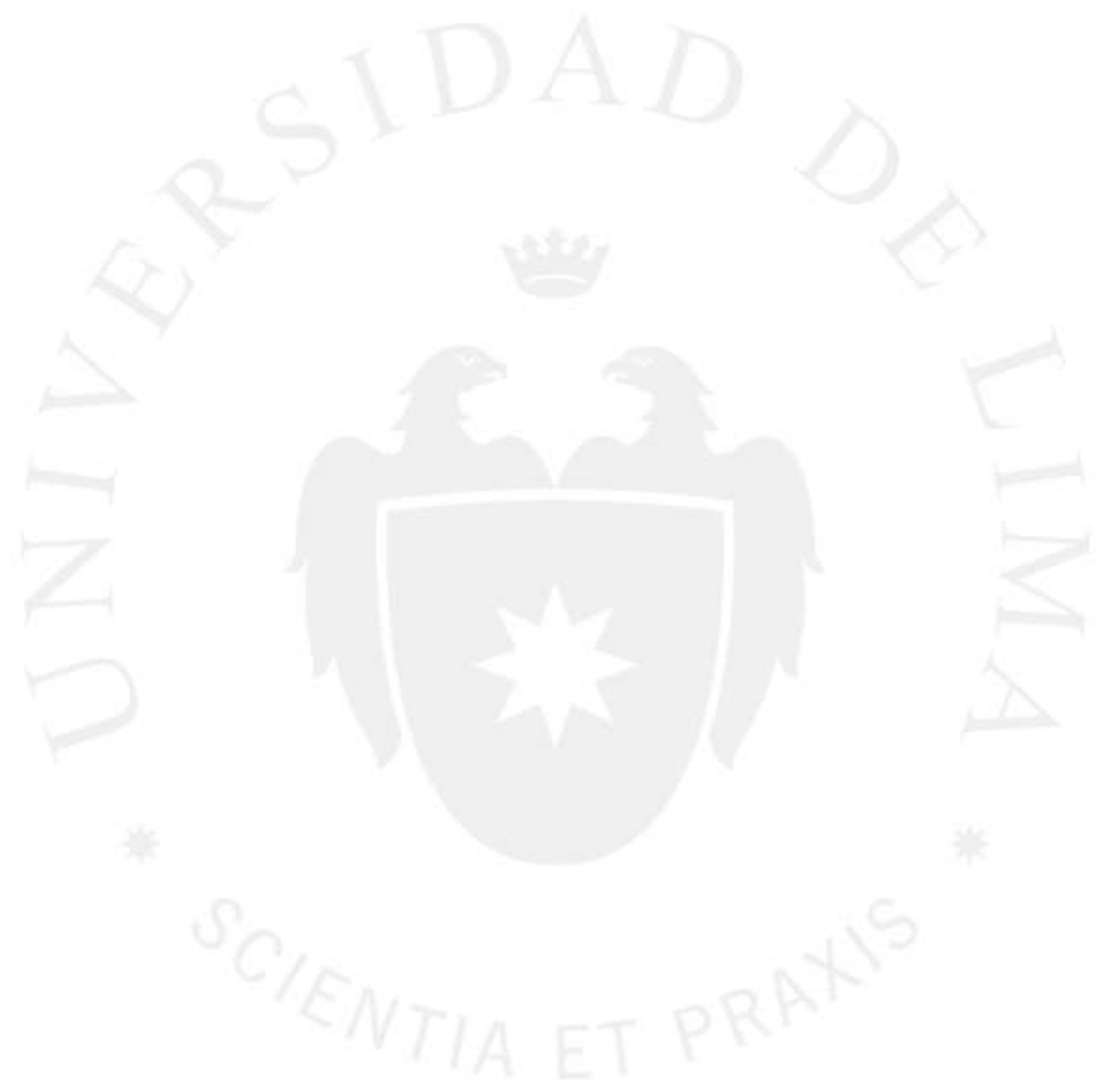




\section{CAMAPAÑA DE LANZAMIENTO DE LA CERVEZA SIN ALCOHOL LEICHT CERO}




\section{ÍNDICE}

pág 5.

1. Definición del Producto .pág 7.

2. Público objetivo pág 7.

2.1 Perfil Psicográfico pág 8.

2.2 Perfil Tecnográfico pág 10.

2.3 Principales Percepciones del Consumidor ..pág 11.

3. Posicionamiento .pág 12.

4. Objetivos de Comunicación pág 12.

5. Propuesta de Valor de la Marca .Pág 12.

6. Identidad de Marca .pág 13.

6.1 Variaciones en el logo .pág 16.

6.2 Presentaciones pág 17.

7. Competencia pág 19

7.1 Competencia directa pág 20.

7.1.1 Edinger Alkoholfrei ................................. pág 21.

7.1.2 Bitburger Drive ................................ pág 22.

8. Objetivo de la campaña ................................................. 23.

9. Estrategia Creativa ................................................pág 23.

9.1 Concepto Creativo ...................................... pág 24.

10. Estrategia de Medios .............................................pág 25.

10.1 Etapa de Intriga ...........................................pág $28 .$.

10.1.1 Publicidad en Vallas Móviles ...........................pág 28.

10.1.2 Influencers .................................. pág 28.

10.2 Etapa de Lanzamiento .........................................pág 29.

10.2.1 Página Web ..............................................pág 29.

10.2.2 Vallas Publicitarias Estáticas ...............................pág 30.

10.2.3 Redes sociales .......................................... pág 32.

10.2.4 Display ................................................ pág 37.

10.2.5 Search ............................................... pág 37.

10.2.6 Anuncio en Publimetro ..................................pág 38 
10.2.7 Spot de Televisión ..............................................ág 38.

10.2.8 Publicidad en Apps ............................................. 41.

10.2.8.1 Waze ................................................... 41.

10.2.8.2 Spotify ........................................... pág 42.

10.2.9 Radio ..................................................... pág 42.

10.2.10 BTL ......................................................... pág 43

10.2.10.1 Degustaciones ......................................pág 43

10.2.10.2 Activaciones en Ofícinas ............................. .pág 43.

10.2.10.3 Sampling en Publimetro ..............................pág 44.

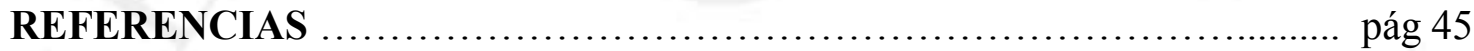

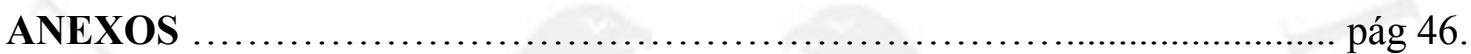




\section{RESUMEN}

El presente trabajo buscar proponer una campaña de lanzamiento de una marca alemana de cerveza sin alcohol que desea incursionar en el mercado peruano. A lo largo de toda la propuesta se busca comunicar la personalidad de marca, resaltando su aspecto divertido y desenfadado. Para la realización de la campaña, se consideró conveniente desarrollar los siguientes puntos: investigación de mercado, estudio del consumidor, propuesta de identidad gráfica, elaboración de estrategia y concepto creativo y estrategia de medios. 


\section{Definición del producto}

Leicht Cero es una marca alemana de cerveza lager sin alcohol que va incursionar en el mercado peruano. Tiene un color amarillo dorado y se caracteriza por ser ligera con un sabor entre dulce y amargo. Cuenta con dos presentaciones, una botella de vidrio de $310 \mathrm{ml}$ que tiene un costo de $\mathrm{S} / 5.50$ y la lata de aluminio de $355 \mathrm{ml}$. a S/6.50 soles; además de los six pack de cada una. Los puntos de venta son los supermercados Wong, Vivanda, Plaza Vea y Tottus, tiendas Listo, Repshop, Viva y Tambo.

La marca busca proyectar una personalidad alegre y desenfadada, sin dejar de lado la calidad del producto ya que no contiene alcohol y mantiene ese sabor característico de la cerveza que tanto le gusta al joven peruano.

\section{Público Objetivo}

El público objetivo definido en el brief son hombres y mujeres de 18 a 35 años de nivel socioeconómico A y B.

Se decidió aprovechar una nueva oportunidad de consumo, ya que el peruano es un bebedor asiduo de cerveza y existen ocasiones en las que puede tener deseos de tomarla pero por su estilo de vida ocupado, especialmente por el trabajo y las responsabilidades que conlleva, además de la políticas de tolerancia cero a la hora de manejar, no puede ingerir alcohol. Asimismo, según un artículo de El Comercio, que se citará líneas abajo, y las encuestas realizadas previamente, el mercado peruano aún tiene cierto recelo para la introducción de este nuevo producto, ya que por más que tiene el interés de cuidar su salud, le da vergüenza ser visto consumiendo una cerveza sin alcohol o no le encuentra sentido de tomarla.

Por ello, se busca entrar poco a poco a este mercado, aprovechando esas oportunidades en las que el target busca relajarse y quiere disfrutar de una cerveza pero no puede, buscando crear un hábito a largo plazo y promoviendo un consumo responsable.

Se ha elegido concentrar mayores esfuerzos de comunicación a los adultos jóvenes de 18 a 35 años de NSE AB que trabajen, ya sea como practicantes o contratados, ya que hay un gran porcentaje de ellos que se desempeña como colaborador en empresas privadas, por lo que están expuestos a una 
vida laboral agitada, debido a que cumplen con un horario establecido y tienen más restricciones para relajarse en el momento que ellos quieran.

Para conocer mejor sus percepciones y estilos de vida, realizaremos un perfil que nos ayude a conocer mejor a nuestro target y que justifique los datos comentados previamente.

\subsection{Perfil Psicográfico}

De acuerdo al perfil del adulto joven peruano realizado por Ipsos en el 2018, se sabe que en promedio tiene 27 años, el $33 \%$ es soltero y sin pareja, y del $66 \%$ que tiene pareja, el $27 \%$ vive con ella. Además, tres de cada cinco adultos jóvenes son padres y tienen en promedio un hijo. (Ipsos, 2018)

Respecto al nivel de educación que tiene dicho grupo, dos de cada cinco adultos jóvenes tiene escolaridad completa. Un tercio ha concluido los estudios superiores, sobretodo de los NSE A y B. De aquellos que están estudiando actualmente, la mayoría lo hace en un instituto superior o una universidad privada. (Ipsos, 2018). El 66\% de adultos jóvenes que están estudiando o terminaron la universidad tiene intención de seguir un estudio de postgrado en los próximos doce meses. (Ipsos, 2018). Esto refuerza el argumento presentado anteriormente sobre el estilo de vida ocupado del target.

En cuanto al ámbito laboral, el $65 \%$ de adultos jóvenes se encuentra solo trabajando, mientras que el 19\% trabaja y estudia. Asimismo, El 61\% de adultos jóvenes se desempeña como colaborador en alguna empresa privada, mientras el 22\% son trabajadores independientes. (Ipsos, 2018)

El estudio de Ipsos revela que el principal medio de entretenimiento en casa es la televisión, seguido por pasar tiempo con la familia, estar en redes sociales y escuchar música. (Ipsos, 2018).

Para divertirse fuera de casa, la actividad que más realizan los adultos jóvenes es salir a comer (43\%), seguido de ir a un parque (38\%), hacer ejercicio (37\%), cine (34\%), ir a la casa de amigos o familia (28\%), ir a bailar (25\%) y por último salir a tomar tragos (9\%). (Ipsos, 2018).

Por otro lado, según el estudio de estilos de vida de Nielsen, los consumidores de todas las edades están empeñados en llevar vidas más sanas, y muchos de ellos lo hacen al elegir opciones de comida más saludable. Más de la mitad de los participantes de todas las generaciones 
dicen estar dispuestos a pagar un precio premium por comida con beneficios a la salud y los participantes más jóvenes son líderes en esta decisión. Pero mientras ciertos atributos saludables como "bajo en sodio" o "bajo en azúcar" parecen ser más atractivos para los consumidores mayores, los atributos como "orgánico" o "libre de gluten" y "alto en proteína" son los que cautivan a los participantes más jóvenes. (Nielsen, 2015)

Las consultoras Nielsen y Kantar confirman el auge de la tendencia hacia un consumo saludable. En América Latina, el 17\% de la canasta familiar corresponde a productos saludables, con países como Brasil, Chile y México creciendo a una tasa superior al $8 \%$ anual en esa categoría. Según Renata Segovia, Solutions Manager de Kantar Worldpanel, se trata de una tendencia global con impacto en toda la región que involucra "modificar hábitos alimenticios", con familias de ingresos elevados y medios, así como parejas con pocos hijos y alto nivel educativo encabezando la tendencia.

Asimismo, según un artículo del Comercio: "El Global Monitor de Kantar Futures ha comprobado que el $78 \%$ de los consumidores de cerveza en todo el mundo trata de cuidar su salud o están de acuerdo en que tienen que hacerlo. Esto representa una oportunidad en la que se han fijado las marcas. Pero cambiar no es tan sencillo, especialmente en el caso de los hombres, explica la consultora. Las cervezas sin alcohol o de baja graduación están empezando a ganar terreno en el mercado, sobre todo entre hombres. Sin embargo, muchos no quieren mostrar que beben este tipo de cerveza porque se avergüenzan y se debaten entre el deseo de reducir la ingesta de alcohol y el miedo a que los demás los vean. (Redacción, 2017)

Además, según la entrevista realizada al maestro cervecero que elaboró la primera cerveza sin alcohol en España, Juan Antonio Corchón, en el sitio web de la marca española Ámbar, "A escondidas como con pudor, así se empezó a tomar la cerveza sin alcohol en España en el año 76. Alguno dirá que es la reacción más normal, pues 40 años después también se siente vergüenza cuando tienes que pedir una cerveza sin alcohol. Lo cierto es que superadas las preguntas de escepticismo más obvias (¿cerveza sin alcohol?, ¿esto qué es?) la aceptación social de las Sin fue creciendo y hoy están tan asentadas que un 14\% de la cerveza que se consume en España no tiene alcohol." (Redacción, 2016). De igual forma que en el mercado español, se busca que exista aceptación a futuro en el mercado peruano; sin embargo, se tiene en cuenta las diferencias entre ambas culturas. 
Asimismo, según el diario Perú21, de acuerdo a los resultados de la más reciente encuesta de Datum "El sondeo indica que el 55\% de los millennials peruanos se alimenta indebidamente y consume comida chatarra, más del $50 \%$ de esta generación no se preocupa por lo que come". Esto indica que a pesar de la tendencia global de consumo saludable, específicamente el joven peruano, ya sea por vergüenza o por falta de interés, aún no está dispuesto a cambiar sus hábitos de consumo alimenticio. Por ello es que no se busca competir contra las cervezas convencionales y se desea entrar al mercado como una alternativa para esos momentos complicados en los que nos antojamos de una cerveza.

Por otro lado, siguiendo los estilos de vida clasificados por Arellano, el target se encuentra dentro de "Las Modernas" y "Los sofisticados".

Las modernas son mujeres que trabajan o estudian y que buscan su realización personal también como madres. Se maquillan, se arreglan y buscan el reconocimiento de la sociedad. Son modernas, reniegan del machismo y les encanta salir de compras, donde gustan de comprar productos de marca y, en general, de aquellos que les faciliten las tareas del hogar. Están en todos los NSE. (Arellano, 2016)

Los sofisticados son un segmento mixto, con un nivel de ingresos más altos que el promedio. Son muy modernos, educados, liberales, cosmopolitas y valoran mucho la imagen personal. Son innovadores en el consumo y cazadores de tendencias. Le importa mucho su estatus, siguen la moda y son asiduos consumidores de productos "light". En su mayoría son más jóvenes que el promedio de la población. (Arellano, 2016)

\subsection{Perfil Tecnográfico}

Con este perfil se busca conocer la relación que tiene nuestro público objetivo con la tecnología y su forma de utilizar las redes sociales. Se sabe bien que las actividades relacionadas a lo digital, como el uso de redes sociales, Whatsapp, Youtube o Spotify, son predominantes en adultos jóvenes de NSE AB y del rango de edad de 21 a 30 años (Ipsos, 2018).

Según el Perfil de Usuario de Redes Sociales realizado por Ipsos, los usuarios de 18 a 24 años tienen una conexión a internet intensiva. Suelen ingresar a redes sociales en su centro de estudios y empiezan a acceder más 
desde el smartphone. Dos de cada cinco suele seguir a algún influencers en las redes. Usan habitualmente Facebook (85\%), Whatsapp (74\%), Youtube (20\%), Instagram (19\%). El 19\% son fans de marcas en redes sociales y $36 \%$ se ha visto influenciado en las compras. (Ipsos, 2018)

Asimismo, los usuarios de 25 a 35 años suelen ingresar a redes sociales desde el trabajo y a través del smartphone y laptop. Uno de cada cinco sigue a un influenciador en redes. Usan habitualmente Facebook (91\%), Whatsapp (59\%), Youtube (27\%), Google + (14\%). El 12\% son fans de marca en redes sociales y el $28 \%$ se ha visto influenciado en las compras. (Ipsos, 2018).

Además, los usuarios de NSE AB se conectan de forma intensiva a internet. Suelen acceder a redes sociales en el trabajo y en movimiento (además del hogar). Facebook, Whatsapp, Youtube e Instagram son las redes sociales utilizadas con mayor cotidianidad y es el grupo que más sigue a influencers. (Ipsos, 2018)

Por otro lado, el usuario activo de Facebook es un Millenial de 37 años, es soltero y trabaja de forma dependiente. Sin embargo, existe un gran porcentaje (46\%) de usuarios activos en Facebook de 18 a 35 años. Asimismo, el usuario activo de Instagram es un Millenial de 30 años que pertenece a los NSE AB, es soltero y trabaja de forma dependiente. Además, el usuario activo de Twitter es un hombre Millenial de 31 años, es soltero y trabaja de forma dependiente. (Ipsos, 2018).

\subsection{Principales percepciones del consumidor}

En base a las 36 encuestas realizadas a personas que son parte del público objetivo, se obtuvieron las siguientes conclusiones:

- El sabor es el factor más importante a la hora de elegir una cerveza.

- Los adultos jóvenes asocian la cerveza con fiesta o reuniones sociales, además de almuerzos de fines de semana.

- La frecuencia con la que nuestro público objetivo consume cerveza es alta, siendo una vez por semana la respuesta más escogida, lo que concuerda con el estudio realizado por Euromonitor que indica que el Perú se encuentra entre los cinco países de mayor consumo per cápita en la región.

- Los encuestados afirman que dentro de las ocasiones en las que han querido tomar cerveza y no han podido se encuentran: cuando están en el trabajo, cuando toman medicamentos, en la universidad, 
almuerzos en días laborales, días de semana por la noche, después de las $11 \mathrm{pm}$ y cuando tienen que manejar.

- La gran mayoría asegura que el sabor es uno de los motivos por el cual prefiere tomar una bebida alcohólica en vez de una bebida sin alcohol, lo cual ratifica que el sabor es imprescindible a la hora de escoger una cerveza. Otros motivo es que asocian el alcohol y sus efectos con relajarse.

- Solo 11 encuestados sabían que venden cervezas sin alcohol en el mercado peruano; de ese grupo, 4 personas probaron y una de ellas fue por confusión, ya que pensó que tenía alcohol.

- Casi todos los encuestados elegirían tomar una cerveza sin alcohol en ocasiones en las que no pueden consumir alcohol. Incluso, hubo un grupo ( 7 personas) que aseguró que no probaría la cerveza bajo ninguna circunstancia.

\section{Posicionamiento}

Para el joven peruano que gusta de la cerveza lager, Leicht Cero es la cerveza de sabor ligero y color dorado que no contiene alcohol, pero sí un sabor similar al que más le gusta en una cerveza. Leicht Cero es su mejor alternativa, para disfrutar de su bebida favorita, sin preocupaciones.

\section{Objetivos de Comunicación}

- Informar sobre el lanzamiento de Leicht Cero, destacando su agradable sabor y que no contiene alcohol

- Informar sobre los puntos de venta de la marca

\section{Propuesta de Valor de la Marca}

Leicht Cero es una deliciosa cerveza sin alcohol y con el sabor que más te gusta, para que disfrutes sin preocupaciones en esos momentos en los que tienes responsabilidades pero también quieres relajarte.

\section{Identidad de Marca}

La nueva identidad de marca es aquella representación o imagen conceptual que un espectador tiene de una organización o empresa, siendo la imagen 
corporativa parte visual de la marca y va más allá de un logotipo, pues la identidad es la imagen, las sensaciones, emociones, filosofía y valores que la empresa desea transmitir hacia el exterior (Costa, 2014, pág. 20)

Para plasmar que es lo que la marca desea transmitir, es necesario empezar por la explicación del nombre. La cerveza se llama Leicht Cero, ya que es una marca proveniente de Alemania. La palabra Leicht significa "ligero" en alemán. Se eligió esta palabra debido a que la cerveza es lagger, es decir es rubia y de baja fermentación, por lo que se entiende que es una cerveza ligera. Asimismo, se utilizó la palabra Cero para el nombre ya que una de las características principales que se desea transmitir es que no contiene alcohol; por otro lado, se dejó la palabra "Cero" en castellano como adaptación al mercado peruano y que sea fácilmente identificada por esta característica.

A continuación se presenta la propuesta del logo para esta nueva cerveza:

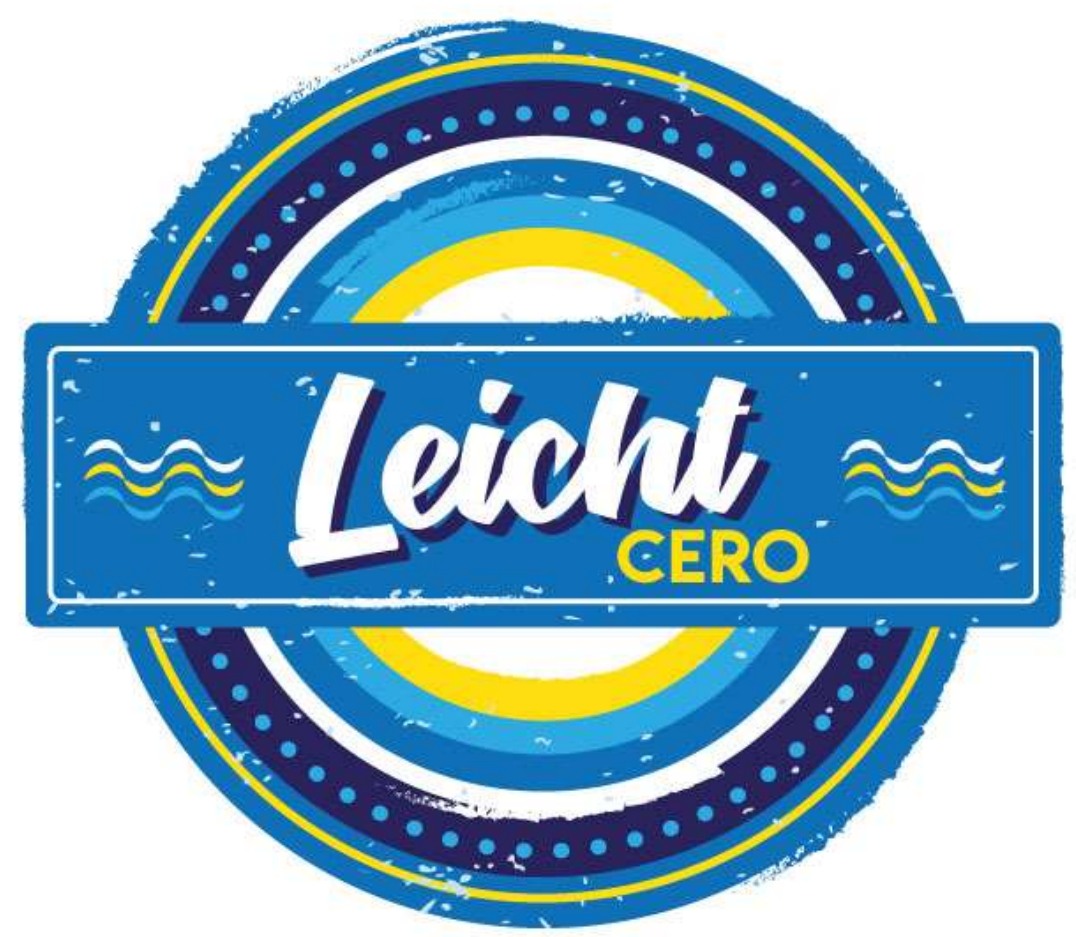

Esta propuesta busca reflejar la personalidad divertida y desenfadada de la marca, pero que al mismo tiempo proyecta calidad. El logo está basado en la forma de un sello de tampón circular, que representa simbólicamente la 
"autorización" o "permiso" para disfrutar de esta cerveza en cualquier situación. Al mismo tiempo, se ha empleado una textura para asemejar la impresión regular que deja un sello sobre el papel y dar esa sensación de libertad que quiere transmitir la marca.

La ligera rotación del logo se emplea para dar un mayor sentido de dinamismo y reforzar la personalidad juvenil de la marca. Los diferentes círculos dentro del logo son la representación visual de las ondas de calor provenientes del sol, lo que refleja la sensación de frescura y relajación que brinda una bebida fría en un día caluroso.

Asimismo, se utilizaron las líneas curvas al costado del nombre para representar las ondas o vibraciones de la buena energía que quiere presentar la marca en señal de relajación y frescura. Se creó con la finalidad de que el posicionamiento de la marca permita en un futuro que Leicht Cero pueda ser reconocida por las ondas sin la necesidad de tener que colocar el logo completo.

La paleta principal se basa en un combinado de colores fríos y cálidos, con la intención de generar un contraste visual, que buscan armonía y equilibrio, así como reforzar las características ya mencionadas de la siguiente manera:

Azul: Este color representa la seguridad que brinda el consumir una cerveza sin alcohol. Además de generar una sensación de frescura y ligereza. Se usaron diferentes tonalidades para que la gráfica no sea plana y pueda generar más contrastes, ya que los espectros del azul aprobados para esta marca, permiten que la gráfica se adecúe sobre cualquier fondo ya sea claro u oscuro. Según el estudio de la psicología del color "El azul a lo largo de la historia ha sido asociado con la pureza, la realeza y los dioses; simbólicamente, es tradicional aplicar el azul al sexo masculino así como también a los grupos intelectuales. Las investigaciones psicológicas con respecto al azul han comprobado que es un color relajante, tranquilizante y que incita a la meditación”. (Villafaña, 2007) 
Amarillo: El uso de amarillo se emplea para representar el color del sol, de la energía, de la amistad. De esta manera, la personalidad de la marca logra transmitir un sentimiento de camaradería con el consumidor. Según la psicología del color "Todos los tonos de amarillo los relacionamos con la naturaleza, desde los marrones de la tierra, hasta los vibrantes rayos del sol, así como con el verano, la primavera y el otoño. Kandinsy afirmaba que un círculo amarillo revela un movimiento de expansión desde el centro hacia el exterior y se acerca marcadamente al espectador. (Villafaña, 2007)

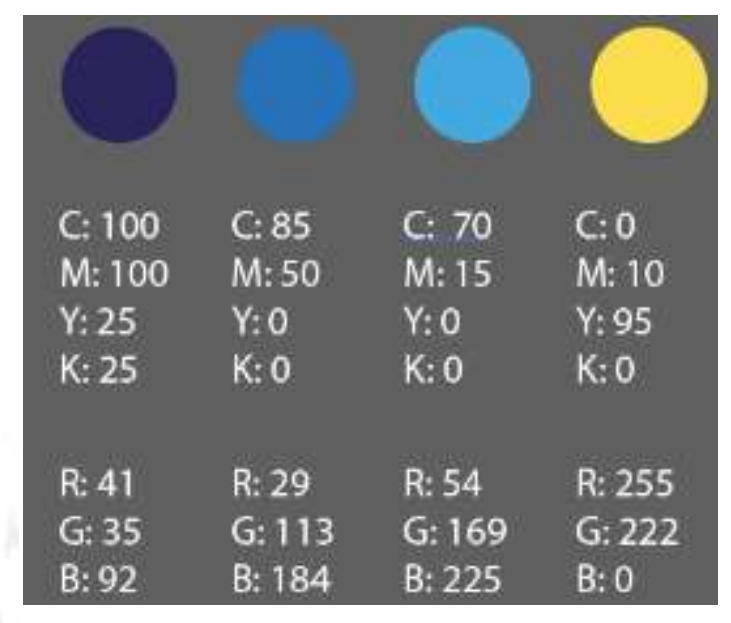

La tipografía utilizada para la palabra "Leicht" es Body and Soul. Tiene un trazo que parece hecho a mano alzada, lo que refleja ligereza, juventud y despreocupación. Por otro lado, para la palabra "Cero" se utilizó Myriad Pro, que es una tipografía tradicional sin serif que demuestra seriedad y seguridad. El grosor que se utiliza en ambas tipografías es intermedio, por lo que la hace legible a una distancia considerable y de fácil lectura para el público en general. El uso de ambas tipografías ayuda a una construcción de marca más balanceada por los conceptos que representan y con mayor contraste visual para llamar la atención del público.

\subsection{Variaciones en el Logo}

Cuando se quiera reproducir el logotipo, es necesario que no se altere el reconocimiento de la marca, ni infrinja el efecto visual que se busca dar al logo desde que fue diseñado. Por ello, se debe tener en cuenta algunas reglas sobre los usos correctos del logotipo.

Debido a que el logo oficial tiene muchos elementos y puede ser un poco complicado a la hora de reproducirlo en algunos fondos o formatos, se han hecho dos variaciones que puedan ser utilizadas sin alterar la identidad de la marca. 
El logo con pastilla se utilizaría para situaciones más formales como en hojas membretadas, contratos, boletas, o también puede usarse en merchandising que tenga poco espacio para la recreación del logo.

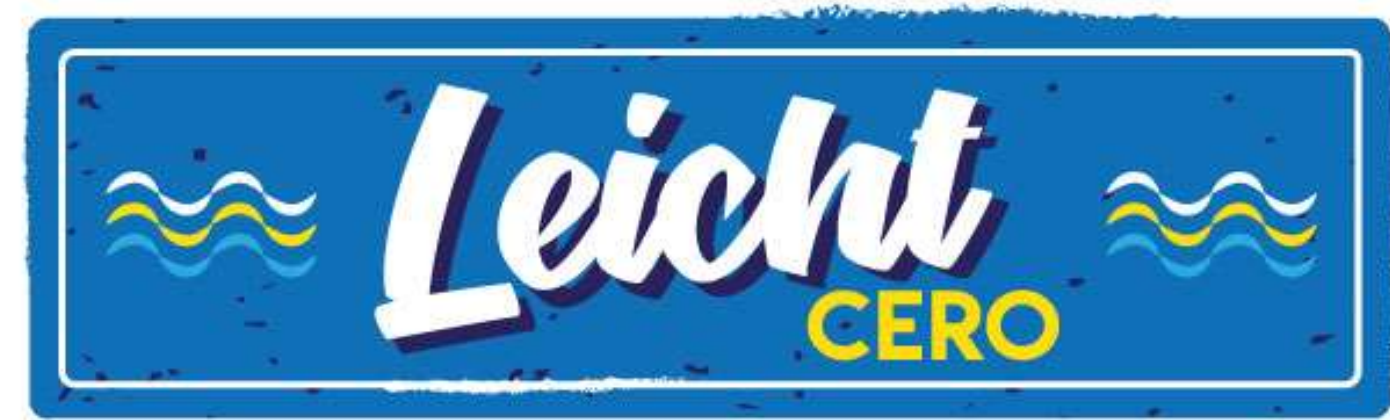

El logo a un solo color

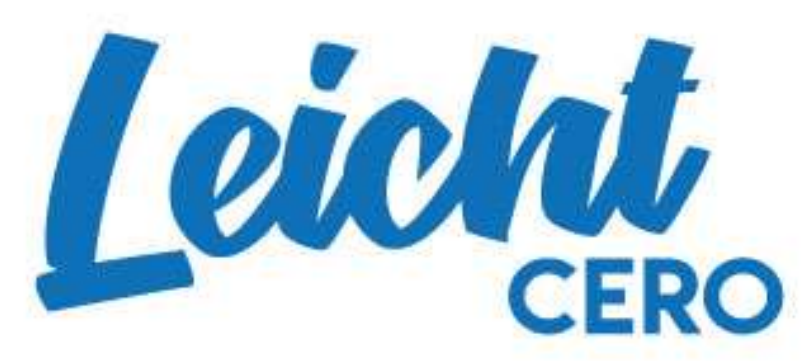

\subsection{Presentaciones:}

Se elaboró dos presentaciones para la marca de cerveza Leicht Cero, la botella de $310 \mathrm{ml}$, la lata de $355 \mathrm{ml}$ y los sixpacks de cada una. Ambas cuentan con gráficas ligeras, es decir, con pocos elementos con el fin de reforzar el nombre que significa ligero en alemán. En el caso del sixpack y de la lata, está permitido el uso de color degradado ya que se trabaja con un fondo blanco, debido a que ya de por si el logo tiene bastantes elementos. Si se utilizara un color entero se vería sobrecargado, por ello, es que el blanco hace contraste con el logotipo y lo resalta.

En el caso de la botella, se utilizó la botella de color oscuro debido a que son las más tradicionales, ya que son las que se utilizaban desde un principio 
por lo que proyecta calidad. Por ello, el diseño de la etiqueta equilibra ese elemento conservador, dándole una personalidad más divertida a la marca.

Asimismo, se utilizó estas líneas curvas en la parte inferior de los empaques como parte de la identidad de la marca. Como se explicó anteriormente, se busca que el consumidor pueda reconocer este elemento y lo asocie con Leicht Cero, por ello está presente en todos los empaques, cambiando de color acorde al fondo en donde se sobreponga, siempre respetando los colores corporativos de la marca.
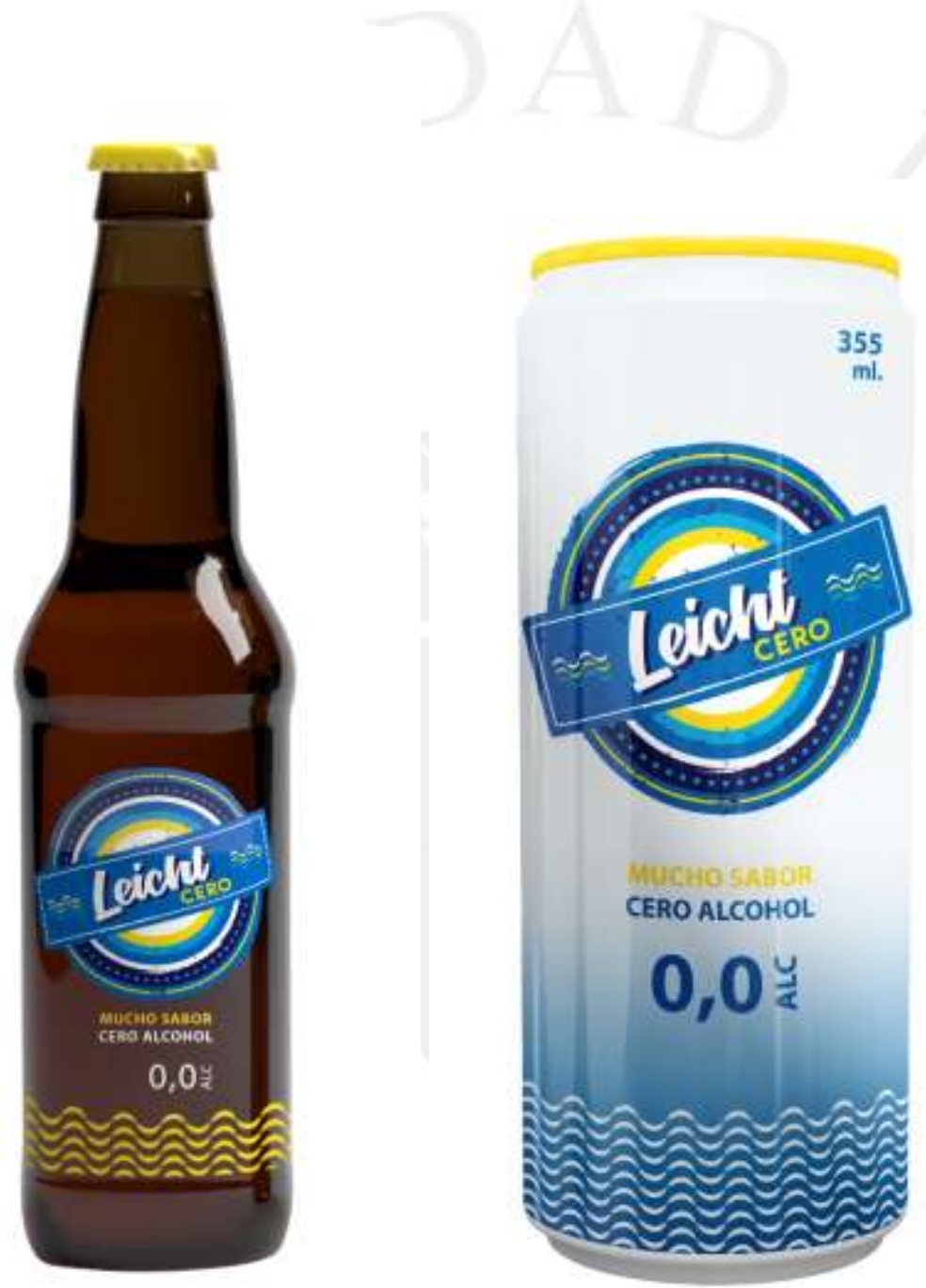

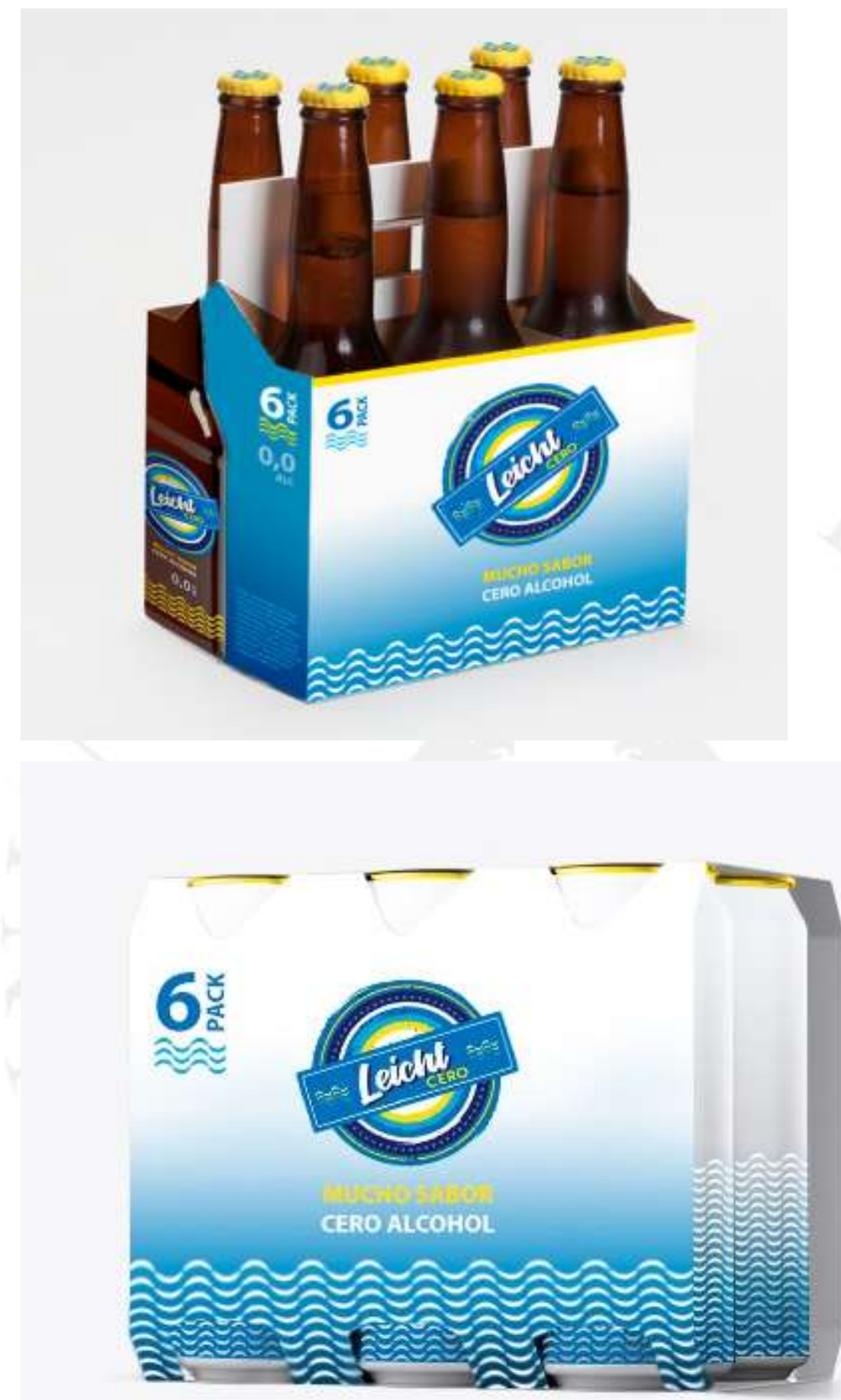

\section{Competencia}

Si bien es cierto que Leicht Cero es una cerveza, se busca ser líder en el mercado de bebidas no alcohólicas; por ello, se consideró conveniente hacer un resumen de los productos que pertenecen a este mercado y podrían ser consumidos como sustitutos de esta cerveza. 
Según un artículo de El Comercio, existió un crecimiento de ventas en las principales categorías de bebidas no alcohólicas entre el 2012 y 2017. A continuación, se mencionará brevemente qué bebidas se encuentran dentro de esta categoría:

- Té: La venta de estos productos creció en $102,8 \%$ en el periodo analizado. Mientras que en el 2012 el consumo per cápita fue 1.4 litros, en el 2017 ascendió a 2.7 litros. Frea Tea, Lipton y Beberash fueron las marcas más vendidas de la categoría. (Redacción, 2017)

- Bebidas Energizantes: La venta de estos productos creció 82.6\% en cinco años. El consumo per cápita de estas bebidas pasó de 3.8 litros en 2012 a 6.4 en 2017 (+68\%). Las marcas más vendidas fueron Gatorade, Sporade y Powerade. (Redacción, 2017)

- Jugos: Las ventas en este segmento crecieron 12.2\% entre 2012 y 2017. Durante ese periodo el consumo per cápita pasó de 11.7 a 12.3 litros $(+5 \%)$. Las marcas más vendidas fueron Frugos, Cifrut y Pulp. (Redacción, 2017)

- Agua Embotellada: Las ventas crecieron en un 52.3\% en el periodo estudiado. Los peruanos pasaron de consumir 16.3 litros per cápita en 2012 a 23.3 en 2017 (+43\%). Euromonitor señaló que las marcas más vendidas fueron Cielo, San Luis y Aquarius. (Redacción, 2017)

- Bebidas Gaseosas: La venta de estos productos creció un 16\%. Según Euromonitor, el consumo per cápita pasó de 47.4 litros en 2012 a 51.5 en 2017 (+9\%). Las marcas más vendidas, de acuerdo a Euromonitor, fueron Coca Cola, Inca Cola y Kola Real. (Redacción, 2017).

\section{1.- Competencia Directa:}

En el mercado peruano, solo existen dos cervezas que no contienen alcohol. A continuación se presentará una breve descripción de ambas marcas y sus posicionamientos. 


\subsection{1 - Erdinger Alkoholfrei}

Erdinger es una empresa privada familiar alemana que ofrece una amplia variedad de cervezas. Esta nació en 1886 y para 1949 ya contaba con el nombre con el que se le conoce actualmente. Entre sus distintas versiones de cerveza, se encuentra Erdinger Alkoholfrei, que está posicionada como "La cerveza para deportistas", ya que apela a sus propiedades saludables e isotónicas, baja en calorías y que actúan como energizante, encajando a la perfección con el estilo de vida de su consumidor. Además, destaca su buen sabor y frescura.

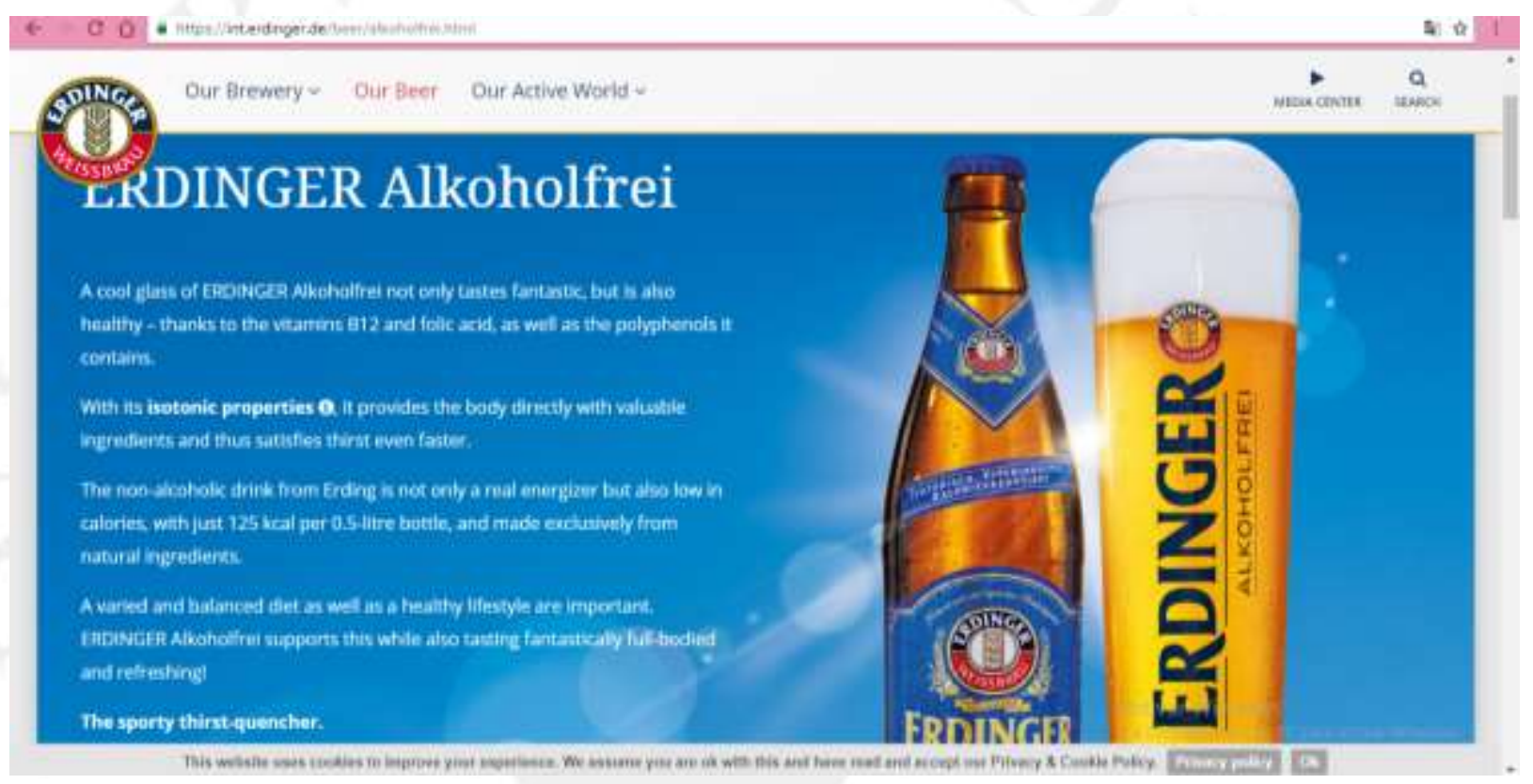

Página web: https://int.erdinger.de/beer/alkoholfrei.html

Erdinger ha logrado crear una comunidad "Team Erdinger Alkoholfrei" que participa de los eventos deportivos que organiza la misma marca en distintos países de Europa y América. En estas maratones, triatlones y eventos de ciclismo, los participantes reciben una cerveza al pasar la línea de meta, como tradición del evento.

Sin embargo, en el Perú no ha habido un lanzamiento aún ya que la marca carece de comunicación. En redes sociales no existe Erdinger Alkoholfrei Perú; sin embargo, si de otros países latinoamericanos. Se vende en Plaza Vea y Wong en una sola presentación, la botella de vidrio de $330 \mathrm{ml}$. y está a un precio de 9.50 nuevos soles. 


\subsubsection{Bitburger Drive}

Bitburger es una empresa familiar alemana que se dedica a la fabricación de cerveza. Fue fundada en 1817 y distribuye sus productos en varios países del mundo. Bitburger Drive es una de sus versiones de cerveza que ofrece una bebida no alcohólica bajo el slogan "Cero alcohol, cero riesgos". Busca generar diversión responsable ya que puede ser consumida por cualquier persona que busque una alternativa saludable a la hora de brindar, ya que es rica en vitaminas y que posee un efecto isotónico.

\section{Página Web:}

https://www.bitburgerinternational.com/bitburger/products/bitburger-drive$00 /$

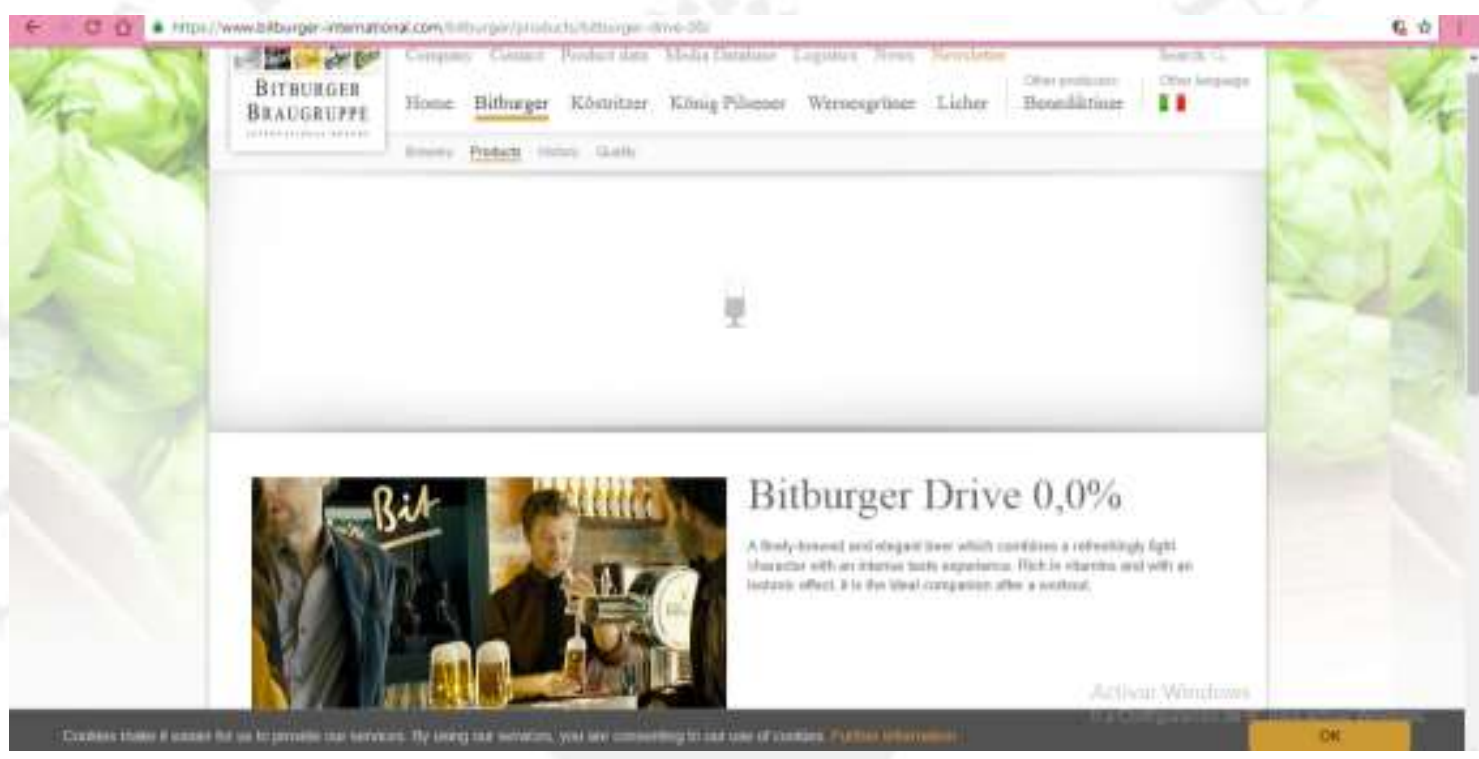

En el Perú existe muy poca información acerca de ella, ya que no ha existido un lanzamiento formal de la marca. En Facebook existe un fanpage de Bitburger Drive Perú y otro de Bitburger Drive para Arequipa. En ambas cuentas, las publicaciones son inconstantes y tienen muy pocos likes e interacciones. En sus post resaltan que la cerveza es para disfrutarla en todo momento. En Instagram tienen cuenta pero no tienen mayor actividad.

Por otro lado, en el 2016 hicieron una alianza estratégica con la banda nacional de rock and roll latino Toño Lopez \& los vintash, en donde se repartía una cerveza por cada entrada a su concierto. Sin embargo, el evento no tuvo mayor repercusión.

Se vende en Plaza Vea, Vivanda y Tottus en una sola presentación, la botella de $330 \mathrm{ml}$. a 6 soles. 


\section{Objetivo de la campaña}

La campaña busca informar sobre el lanzamiento de la nueva cerveza Leicht Cero, dando a conocer su buen sabor y que no contiene alcohol, lo que permite tomarla sin preocupaciones.

\section{Estrategia Creativa}

Qué: Leicht Cero promete ser la cerveza sin alcohol que te permite disfrutar sin preocupaciones en cualquier ocasión que te antojes del rico sabor de una cerveza.

La razón: Hay momentos en los que el target quiere relajarse y disfrutar del sabor de una cerveza, pero por sus responsabilidades y restricciones no puede consumir alcohol. Para esas ocasiones, Leicht Cero es la cerveza indicada: porque no contiene alcohol y mantiene el sabor preferido por los jóvenes, gracias a su proceso de elaboración igual al de una cerveza convencional pero con la diferencia de que al final se le extrae el alcohol, mediante distintos métodos que permiten que el sabor se mantenga igual.

Según un artículo del periódico español El Diario de Valladolid “ Pues aunque parezca un sueño inalcanzable, el grupo de Superficies y Materiales Porosos de la Universidad de Valladolid (UVA) lo ha conseguido y desalcoholiza cervezas con todos sus complementos en el laboratorio. «Los métodos actuales son muy agresivos y, junto con el alcohol, se pueden perder los aromas», expone Antonio Hernández, director del equipo.

Su contribución se centra en recuperar los aromas mediante pervaporación, reservarlos y volverlos a introducir para mantener las propiedades de la bebida. «Los resultados son muy buenos y se han desarrollado en colaboración con distintas empresas y organismos públicos», señala". (Redacción, 2016).

Cómo: La comunicación que tendremos con nuestro público objetivo será racional ya que se busca comunicar el principal beneficio de tomar esta cerveza sin alcohol, que te da libertad para que te relajes sin descuidar tus responsabilidades. 
Tono de comunicación: El tono a utilizar será cercano, divertido y relajado, ya que a través de los medios que se utilizará, se podrá transmitir la personalidad juvenil de la marca.

\subsection{Concepto Creativo:}

Luego de los insights obtenidos de nuestro público objetivo, se decidió trabajar bajo el concepto de "Licencia para Tomar", que apela a la idea de libertad o permiso que se le quiere dar al target en estas situaciones en las que no puede consumir alcohol pero si quiere relajarse y tomar una cerveza con ese sabor característico que tanto le gusta.

Según el diario español La Razón "la cerveza sin alcohol es la bebida preferida entre los cerveceros cuando no quieren o no pueden tomar alcohol. Según la encuesta realizada por Heineken en su portal Let's Beer en noviembre 2016, 9 de cada 10 cerveceros escogen la «0,0» ante cualquier otra bebida, principalmente por su sabor y su naturalidad, al permitirles seguir una alimentación sana disfrutando de todo el sabor de la cerveza, y por la libertad para desarrollar además otras actividades (conducir, trabajar, practicar deporte...), siendo muy adecuadas para cualquier momento del día o de la noche.” (Ruiz, 2017)

Este es el motivo por el cual durante la campaña se hará alusión a estas situaciones, como por ejemplo un almuerzo de trabajo, un día de semana en la noche, manejando o simplemente cuando se tenga alguna actividad que requiera lucidez; Leicht Cero le da "licencia" para disfrutar de esta rica cerveza sin preocupaciones, sin dejar de lado su sabor igual que una cerveza convencional.

\section{Tácticas:}

Se realizarán las siguientes tácticas que ayudarán a cumplir nuestro objetivo de generar Posicionamiento y Awareness.

- Uso de rompetráficos, jalavistas y volantes en los puntos de venta para llamar la atención de clientes potenciales.

- Uso de frases y bajadas publicitarias como "Leicht Cero te da licencia para tomar en la oficina", "Leicht Cero te da licencia para tomar antes de manejar".

- Uso de las situaciones planteadas anteriormente para toda la comunicación de la campaña. 


\section{Estrategia de Medios}

La propuesta de medios se basa en una campaña integral de lanzamiento que estará conformada por una etapa de intriga y otra de lanzamiento. En total tendrán una duración de 3 meses y una semana.

Para la etapa de intriga, se seleccionó publicidad en valla móvil con recorridos estratégicos de la ciudad de Lima e influencers. Será seguida por la etapa de lanzamiento, que iniciará con la implementación de las vallas estáticas en donde se dará a conocer el producto y sus características y la creación de página web, que también busca informar a los usuarios, pero adicionalmente se desea tener una base de datos que nos permitirá a futuro enviarles promociones y segmentar la pauta digital según el público captado. Esto se realizará a través de un sorteo en el que se podrá participar mediante el llenado de un formulario en la web.

Asimismo, se considera esencial que el target conozca y pruebe el producto, de modo que pueda comprobar el buen sabor de Leicht Cero. Por ello, se harán degustaciones en los puntos de venta, en todos los supermercados y tiendas de conveniencia autorizados, de los principales distritos de Lima Moderna como San Isidro, Miraflores, Surco, San Borja, y La Molina. Adicionalmente, se realizarán activaciones a la hora de almuerzo en cafeterías de ocho grandes empresas y se hará sampling con Publimetro, en donde se repartirán latas de la cerveza en puntos estratégicos. Todo ello irá acompañado de la repartición de merchandising, para generar awareness y de volantes para que comunique los puntos de venta y el concurso en el que puedes participar mediante la página web. Los volantes tendrán un código $\mathrm{QR}$, de esta forma logramos conectar los medios online y offline.

Además, se realizará un spot de televisión, habrá publicidad en aplicaciones como Waze y Spotify, se tendrá presencia en la portada de Publimetro. También se hará pauta en redes sociales, Facebook, Instagram y Youtube; además de invertir en Search y Display.

Adicionalmente a los medios pagados en los que estará presente la marca, se considera necesario plantear una propuesta de medios propios que reforzarán la comunicación que se le está dando al nuevo producto, utilizando las distintas redes sociales que tendrá la marca. Dentro de ellas se 
consideran Facebook, Instagram y Youtube ya que son las redes sociales más utilizadas por el público objetivo.

Considerando lo descrito anteriormente, se presenta el presupuesto que se utilizó para el lanzamiento de la campaña.

\begin{tabular}{|l|l|r|l|}
\cline { 2 - 4 } & $\begin{array}{l}\text { EN } \\
\text { DÓLARES }\end{array}$ & \multicolumn{1}{l|}{ VALOR } & EN \\
DÓLAR & SOLES \\
\hline PPTO CAMPAÑA & 450,000 & 3.3 & 148,5000 \\
\hline
\end{tabular}

\begin{tabular}{|c|c|c|c|c|}
\hline ATL & $\begin{array}{l}\text { COSTO } \\
\text { DÓLARES }\end{array}$ & $\begin{array}{l}\text { VALOR } \\
\text { DÓLAR }\end{array}$ & $\begin{array}{l}\text { COSTO } \\
\text { SOLES }\end{array}$ & TOTAL \\
\hline $\begin{array}{l}\text { DESARROLLO DE GUIÓN PARA } \\
\text { SPOT TV Y SPOT RADIO }\end{array}$ & 9,050 & 3.3 & 29,865 & 29,865 \\
\hline $\begin{array}{l}\text { PRODUCCIÓN, REALIZACIÓN Y } \\
\text { EDICIÓN DE SPOT TV }\end{array}$ & 35,000 & 3.3 & 115,500 & 115,500 \\
\hline $\begin{array}{l}\text { PRODUCCIÓN, REALIZACIÓN Y } \\
\text { EDICIÓN DE SPOT RADIO }\end{array}$ & $6,020.67$ & 3.3 & $19,868.211$ & $19,868.211$ \\
\hline PAUTA EN TV (FOX, SONY) & 90,000 & 3.3 & 297,000 & 297,000 \\
\hline $\begin{array}{l}\text { PAUTA EN RADIO (PLANETA, } \\
\text { STUDIO 92, DISNEY) }\end{array}$ & 26,884 & 3.3 & $88,717.2$ & $887,17.2$ \\
\hline $\begin{array}{l}\text { KEY VISUAL DE CAMPAÑA DE } \\
\text { INTRIGA }\end{array}$ & 5,000 & 3.3 & 16,500 & 16,500 \\
\hline $\begin{array}{l}\text { KEY VISUAL DE CAMPAÑA DE } \\
\text { LANZAMIENTO }\end{array}$ & 1,500 & 3.3 & 4,950 & 4,950 \\
\hline $\begin{array}{l}\text { ADAPTACIÓN DE KV PÁGINA } \\
\text { LATERAL EN PORTADA }\end{array}$ & 375 & 3.3 & $1,237.5$ & $1,237.5$ \\
\hline $\begin{array}{l}\text { PUBLICACIÓN PUBLIMETRO } \\
\text { LATERAL EN PORTADA X } 1 \text { DÍA }\end{array}$ & 9,643 & 3.3 & $31,821.9$ & $31,821.9$ \\
\hline $\begin{array}{l}\text { ADAPTACIÓN DE KV VALLAS } \\
\text { ESTÁTICAS VÍA PÚBLICA }\end{array}$ & 500 & 3.3 & 1650 & 1,650 \\
\hline $\begin{array}{l}\text { PUBLICACIÓN DE VALLAS } \\
\text { ESTÁTICAS EN VÍA PÚBLICA X } \\
3 \text { MESES }\end{array}$ & 46,416 & 3.3 & $153,172.8$ & $153,172.8$ \\
\hline & $\$ 230,388$ & & & $/ 760,282.611$ \\
\hline
\end{tabular}

\begin{tabular}{|c|c|c|c|c|}
\hline DIGITAL & $\begin{array}{l}\text { COSTO } \\
\text { DÓLARES }\end{array}$ & $\begin{array}{l}\text { VALOR } \\
\text { DÓLAR }\end{array}$ & $\begin{array}{l}\text { COSTO } \\
\text { SOLES }\end{array}$ & TOTAL \\
\hline $\begin{array}{l}\text { SOCIAL MEDIA (FACEBOOK, } \\
\text { CANAL YOUTUBE, } \\
\text { INSTAGRAM) ADAPTACIONES } \\
\text { PIEZAS GRÁFICAS, } \\
\text { DESARROLLO DE GUIÓN Y } \\
\text { PRODUCCIÓN CON } \\
\text { REALIZACIÓN DE VIDEOS Y } \\
\text { PAUTA) }\end{array}$ & 41,498 & 3.3 & $136,943.4$ & $136,943.4$ \\
\hline $\begin{array}{l}\text { WEB (DISEÑO, COMPRA DE } \\
\text { DOMINIO, ALQUILER DE } \\
\text { SERVIDOR) }\end{array}$ & 10,300 & 3.3 & 33,990 & 33,990 \\
\hline
\end{tabular}




\begin{tabular}{|l|r|r|r|r|}
$\begin{array}{l}\text { DISPLAY (COMPRA DE } \\
\text { AUDIENCIA - FORMATO } \\
\text { BANNER REACH MEDIA) }\end{array}$ & 5,000 & 3.3 & 16,500 & 16,500 \\
\hline INFLUENCERS X 4 & $8,484.84$ & 3.3 & 28,000 & 28,000 \\
\hline PUBLICIDAD EN APPS (WAZE) & 9,000 & 3.3 & 29,700 & 29,700 \\
\hline $\begin{array}{l}\text { PUBLICIDAD EN APPS } \\
\text { (SPOTIFY) }\end{array}$ & 9,000 & 3.3 & 29,700 & 29,700 \\
\hline $\begin{array}{l}\text { SEARCH (SEM, KEY WORD Y } \\
\text { ANUNCIOS EN GOOGLE) }\end{array}$ & 2,500 & 3.3 & 8,250 & 8,250 \\
\hline $\begin{array}{l}\text { PREMIO SORTEO (PAQUETE } \\
\text { DOBLE A PARACAS) }\end{array}$ & 1,000 & 3.3 & 3,300 & 3,300 \\
\hline
\end{tabular}

\begin{tabular}{|c|c|c|c|c|}
\hline BTL & $\begin{array}{l}\text { COSTO } \\
\text { DÓLARES }\end{array}$ & $\begin{array}{l}\text { VALOR } \\
\text { DÓLAR }\end{array}$ & $\begin{array}{l}\text { COSTO } \\
\text { SOLES }\end{array}$ & TOTAL \\
\hline $\begin{array}{l}\text { VALLAS MÓVILES INTRIGA } \\
\text { (RECORRIDO LA MOLINA, SAN } \\
\text { BORJA, SAN ISIDRO, SURCO Y } \\
\text { MIRAFLORES) }\end{array}$ & 757.57 & 3.3 & 2,500 & 2,500 \\
\hline $\begin{array}{l}\text { DEGUSTACIONES } \\
\text { (SUPERMERCADOS WONG X4, } \\
\text { PLAZA VEAX4, VIVANDAX4, } \\
\text { TOTTUSX4, TIENDAS LISTOX4, } \\
\text { REPSHOPX4, VIVAX4 Y } \\
\text { TAMBOX4) } 32 \text { TIENDAS EN } \\
\text { LIMA X } 3 \text { MESES }\end{array}$ & 4,6545 & 3.3 & $153,598.5$ & $153,598.5$ \\
\hline $\begin{array}{l}\text { ACTIVACIONES EN OFICINAS } \\
\text { (08 EMPRESAS GREAT PLACE } \\
\text { TO WORK) }\end{array}$ & 9,600 & 3.3 & 31,680 & 31,680 \\
\hline $\begin{array}{l}\text { MERCHADISING (POCKETS } \\
\text { SMARTPHONES PARA } \\
\text { AWARENESS) }\end{array}$ & 16,700 & 3.3 & 55,110 & 55,110 \\
\hline $\begin{array}{l}\text { ACTIVACIONES CON } \\
\text { PUBLIMETRO X } 20 \text { PUNTOS DE } \\
\text { ENTREGA }\end{array}$ & 46,326 & 3.3 & $15,2875.8$ & $152,875.8$ \\
\hline & $\$ 119,928.57$ & & & S/. 395,764.3 \\
\hline
\end{tabular}

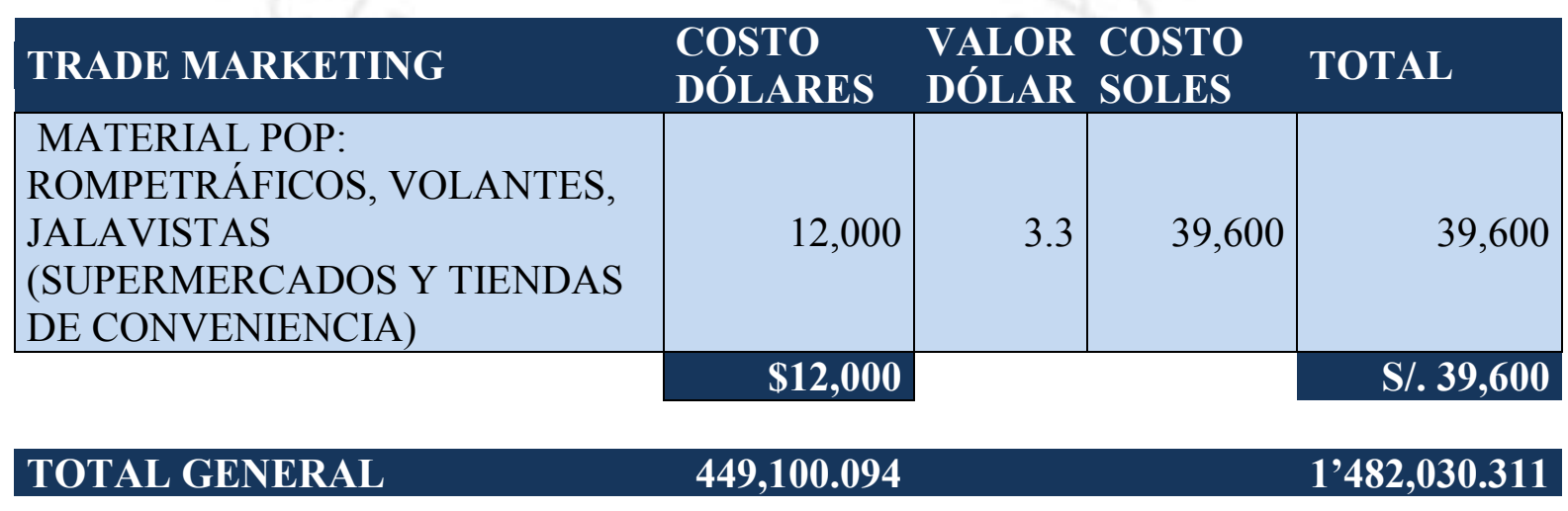




\section{1.- Etapa de Intriga}

Los medios que se recomiendan para esta etapa, que tendrá una duración de 1 semana, son la publicidad en vallas móviles y el uso de influencers.

\subsection{1.- Publicidad en Vallas Móviles}

Se eligió utilizar este medio alternativo porque tiene gran alcance y genera impacto en las personas que lo ven. Se puede segmentar por zonas específicas acorde al target y debido a su movimiento, es más dinámico.

Se emplearán vallas móviles en las zonas específicas en las que se desea impactar al público objetivo. En este caso, se recorrerá las principales calles del distrito de San Isidro, como Camino Real, Domingo Orué, República de Panamá, Canaval y Moreyra, Aramburú y Javier Prado, ya que es donde hay mayor concentración de oficinas y le queremos dar mayor énfasis a los trabajadores; sin dejar de lado a las demás personas que también pertenecen al target, hombres y mujeres de 18 a 35 años de NSE AB; por ello también se recorrerán las principales calles de Lima Moderna, ya que son en las que se encuentra el público objetivo, como Miraflores, San Borja, La Molina y Surco. Los recorridos que se harán será de lunes a viernes de $12 \mathrm{pm}$ a $3 \mathrm{pm}$, debido a que esta es la hora habitual en la que el target suele salir a almorzar y de 5pm a 8pm que suele ser el horario de salida de las personas que trabajan y el recorrido también se hará sábado y domingo de $12 \mathrm{pm}$ a $9 \mathrm{pm}$.

Las vallas móviles tendrán una duración de 7 días. Se utilizarán dos motivos de vallas en total, en las que se busca comunicar las situaciones en las que el consumidor puede querer tomar una cerveza y no puede. En la primera se presenta a un ejecutivo estresado trabajando en su oficina, junto al texto "Pronto licencia para tomar en la oficina". El segundo motivo será un grupo de amigos en un carro, mientras todos están tomando y divirtiéndose, el conductor está aburrido, la gráfica será acompañada del texto "Pronto licencia para tomar antes de manejar".

\subsection{2.- Influencers}

Se seleccionarán cuatro influencers para que participen en las etapas de intriga y lanzamiento. En la primera parte, se busca que hagan stories en Instagram y post de Facebook, que hablen acerca de las situaciones en las que desearían tomar alcohol y no puedan, invitando a sus seguidores a comentar y generar conversación sobre el tema. 
Se eligió a Ximena Galiano y Mateo Garrico Lecca, ambos influencers de comedia, que impactarán en el segmento más joven, hombres y mujeres de NSE AB de 18 a 24 años. Asimismo, se escogió a Luciano Mazeti, reconocido chef peruano y a Stephanie Cayo, reconocida actriz y modelo, para que lleguen al segmento de jóvenes adultos de NSE AB de 25 a 35 años. Todos cuentan con una gran cantidad de seguidores en sus redes sociales.

En la segunda parte, es decir, ya en la etapa de lanzamiento, participarán yendo a las activaciones en empresas y haciendo stories debido a que tienen alcance en sus seguidores e invitando a la gente a participar del concurso que realizaremos.

\subsection{Etapa de Lanzamiento}

Durante esta etapa contaremos con medios propios (Página Web, Fanpage de Facebook, Instagram y Youtube) y medios pagados, que nos generarán medios ganados, ya sea alguna nota de prensa de algún periódico, revista o alguna nota web en un blog de publicidad que comuniquen la campaña de lanzamiento de este nuevo producto.

Se considera conveniente que los medios pagados y los propios guarden coherencia para que la campaña tenga consistencia. A continuación se presentará la propuesta de medios, con el objetivo de generar awareness y posicionamiento de la marca.

\subsubsection{Página Web}

Se considera sumamente necesario que la marca esté presente en digital, pero no solo en redes sociales, sino también que tenga una página web para que pueda ser visible en buscadores y tenga credibilidad ante los clientes potenciales. Por ello, se procederá a comprar un dominio para la exclusividad de la página.

Se busca que la página sea informativa para que los usuarios puedan conocer sobre las características del producto y su personalidad. Por ello, en el menú de inicio de la web se podrá visualizar la historia de la marca, beneficios, puntos de venta, promociones, un botón que te llevará al canal de Youtube y preguntas frecuentes que tienen como propósito acabar con las dudas que tenga el consumidor acerca de esta cerveza sin alcohol. Asimismo, habrá una pestaña adicional con un formulario, en donde los usuarios podrán dejar sus 
datos y entrarán a un concurso por un viaje para dos personas a Paracas un fin de semana con todo pagado. Este concurso se hace con el fin de generar tráfico a la web y que conozcan el producto, además de generar una base de datos, para que a futuro se les pueda enviar promociones y segmentar la pauta digital acorde a la información que recibiremos en el formulario.

\subsubsection{Vallas Publicitarias Estáticas}

Se implementará vallas publicitarias en lugares estratégicos en Lima ya que es importante tener presencia constantemente por ser una marca nueva en el mercado. La ubicación de las vallas será en los mismos distritos en donde circularon las vallas publicitarias móviles para la campaña de intriga: San Isidro, San Borja, Miraflores, La Molina y Surco. Estos espacios serán alquilados por 3 meses.

Para la elección de los motivos, se escogerá tres situaciones planteadas anteriormente en las que el target, hombres y mujeres de 18 a 35 años de NSE AB, tanto los que trabajen en empresas y los que no, quieran disfrutar de una cerveza y no puedan por las restricciones y responsabilidades que tienen. Todos los motivos serán acompañados de la frase "Mucho sabor, cero alcohol" e incluirán los logos de los puntos de venta de la marca. 
Motivo 1: Valla Publicitaria

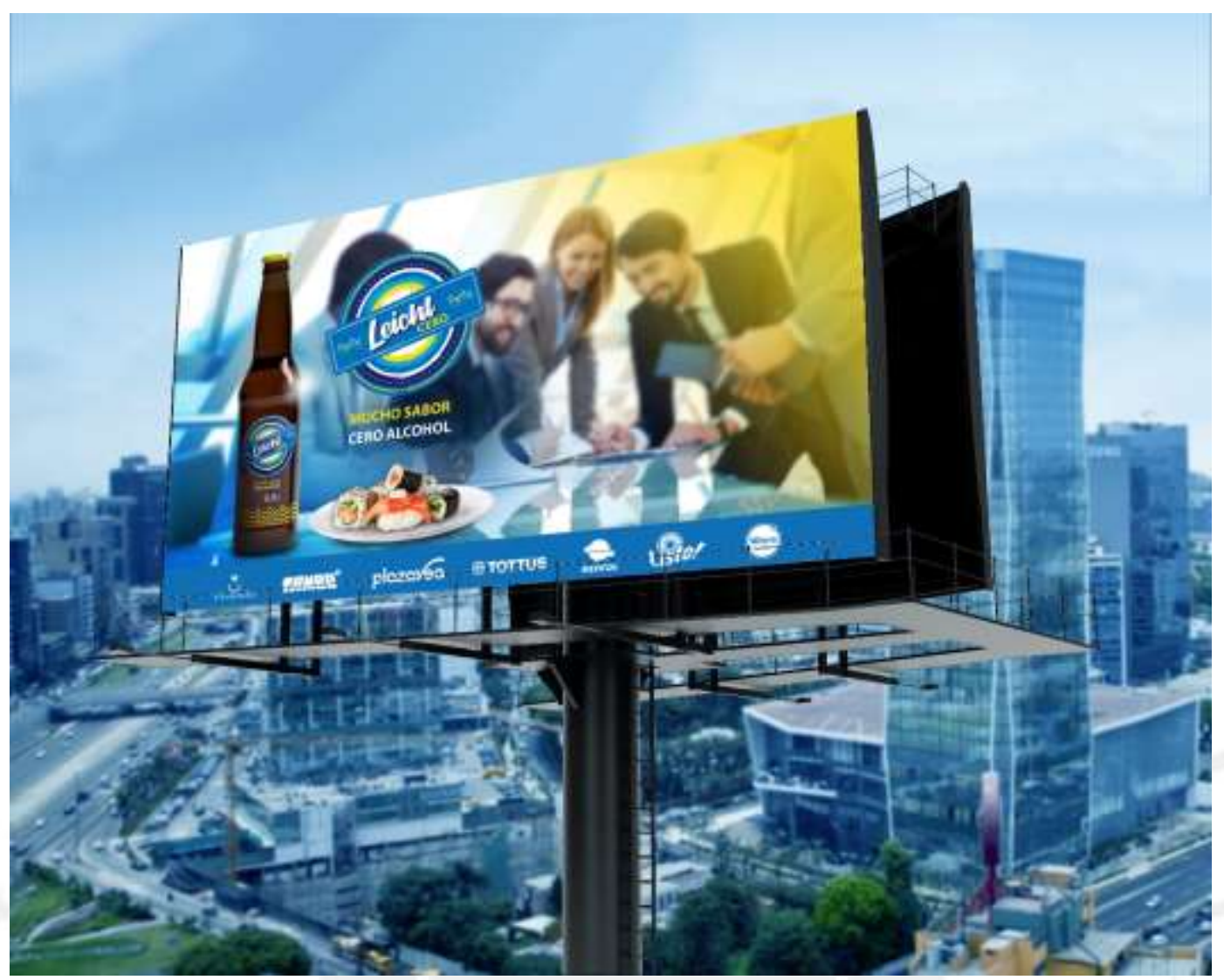

Motivo 2: Valla Publicitaria

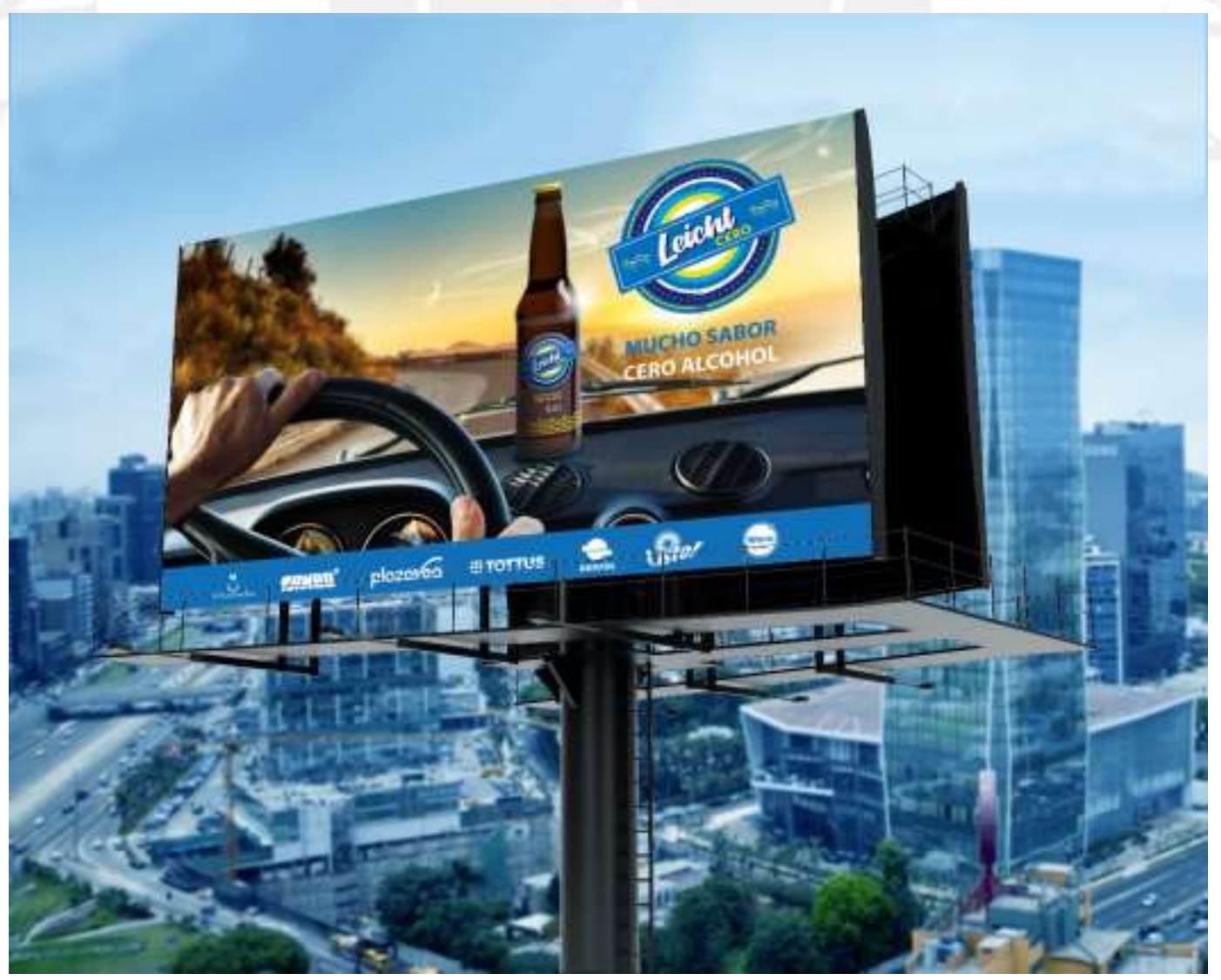




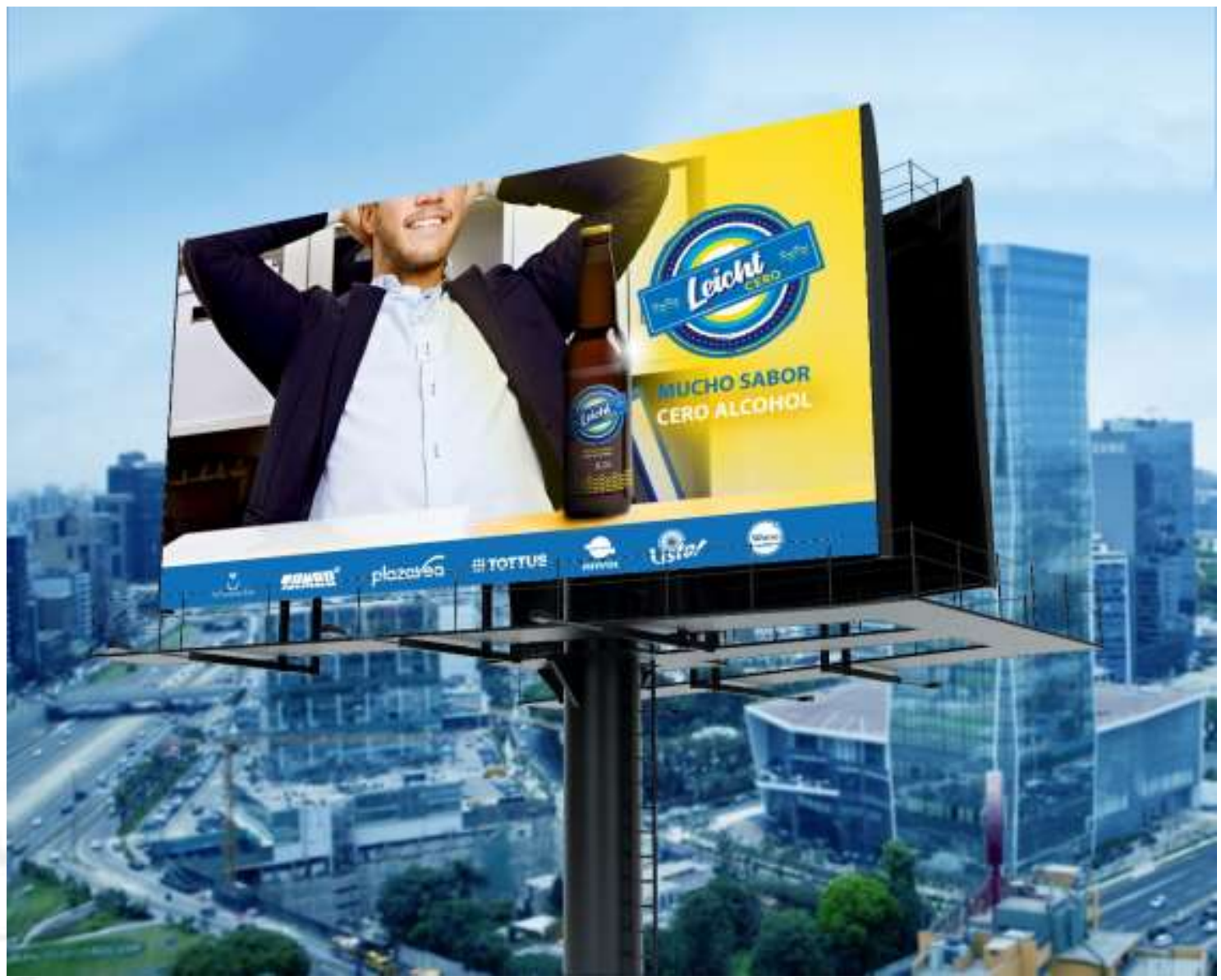

\subsubsection{Redes sociales}

De acuerdo al perfil tecnográfico del joven peruano que se armó previamente, se eligió utilizar Facebook, Instagram y Youtube ya que son las redes sociales más utilizadas por nuestro target. Se creará cuentas en todas las redes mencionadas y se publicará contenido propio que seguirá la misma línea de comunicación que se está haciendo en todos los medios a lo largo de la campaña, adaptando cada formato acorde a la red social utilizada. A continuación se presentará las temáticas generales de contenido que deben seguir los post:

- Situaciones en las que no se puede tomar alcohol

- Beneficios de la cerveza sin alcohol

- Promociones

- Características del producto (Sabor)

Por otro lado, se utilizará dos redes, Facebook e Instagram, como canales para comunicar acerca del concurso y generar leads, y a la vez para que los 
usuarios puedan informarse acerca del producto y sus características mediante la página web.

Para ello se implementará el siguiente formato:

\section{Page Post Link}

Como se explicó anteriormente, con este formato se busca generar leads a través de visitas a la página web mediante la pauta digital que se pondrá en Facebook e Instagram. Se adaptarán las gráficas de las vallas publicitarias de la etapa de lanzamiento al formato de page post link para ambas redes sociales. Esta pauta tendrá vigencia de un mes, ya que ese será el plazo para que los usuarios llenen el formulario y finalice el concurso.

\section{Formato de Facebook:}

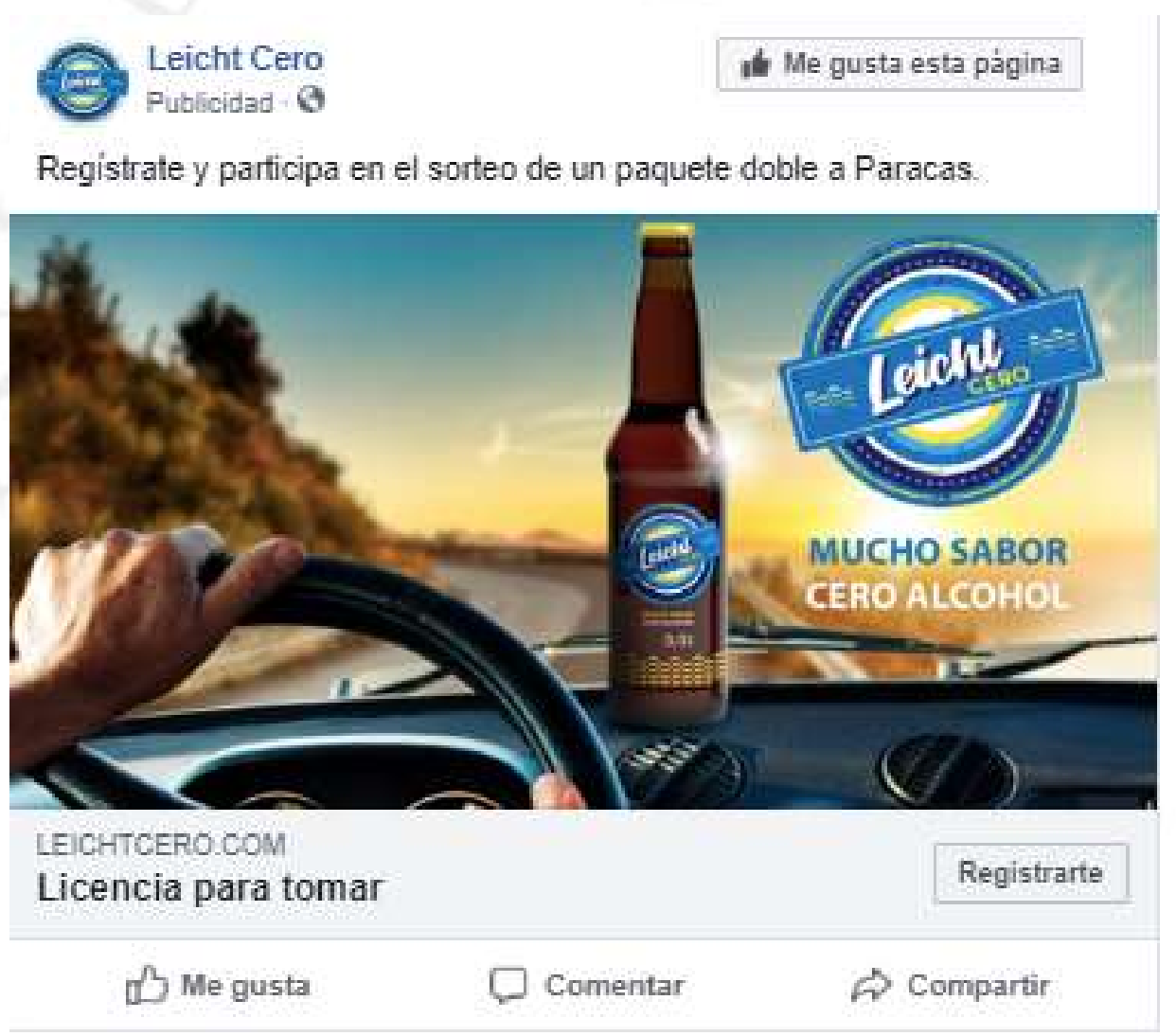




\section{Formato de Instagram}

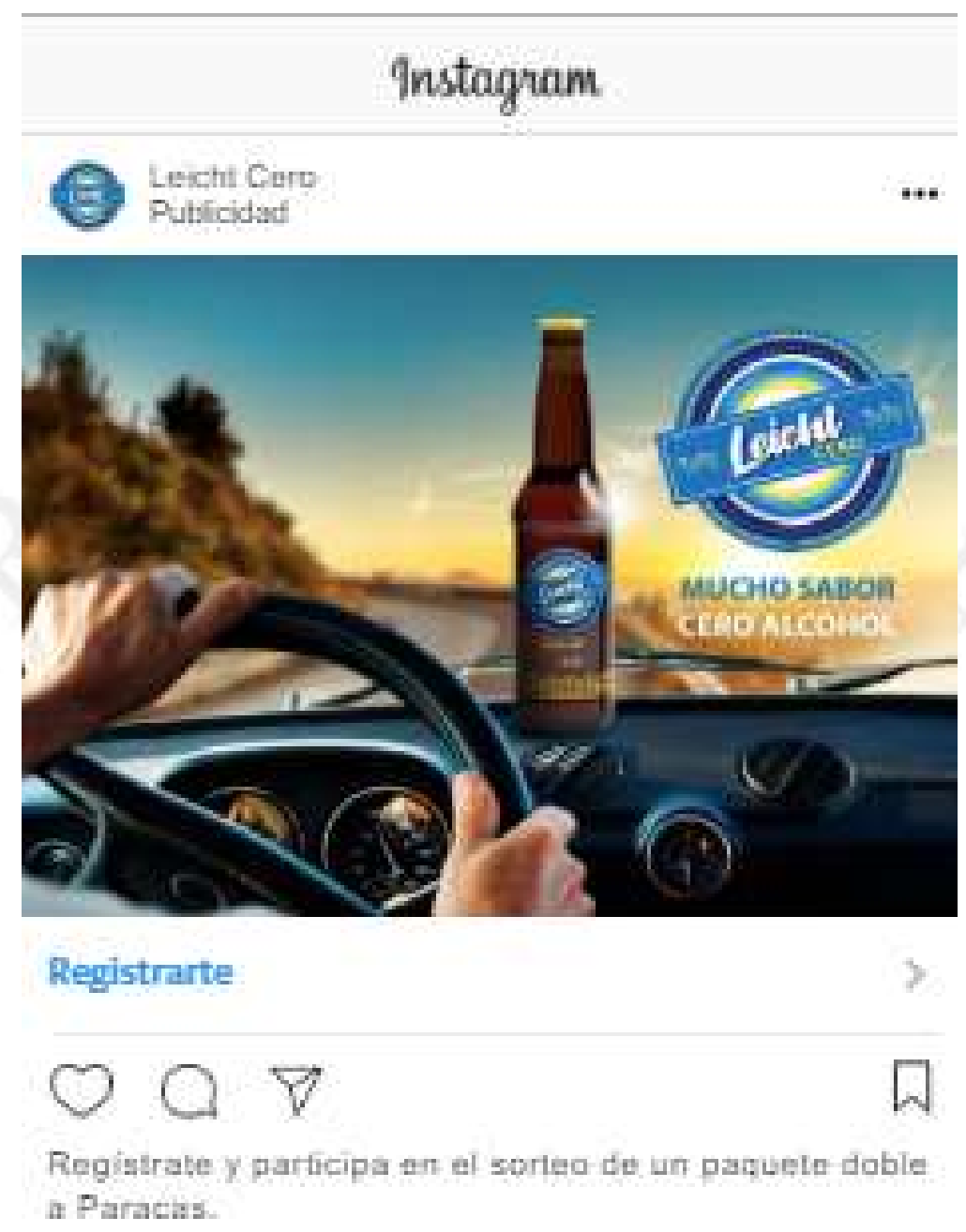

Una vez finalizado el concurso, se implementarán dos tipos de pautas:

\section{Pauta de Base Cerrada:}

Irá dirigida a las personas que llenaron el formulario y están en nuestra base de datos. Como ya entraron a nuestra página web y ya la conocen, se busca ofrecerles contenido interesante en redes para que sigan los fanpage de la página y puedan conocer cualquier novedad o promoción de la marca. Para ello se plantea utilizar el siguiente formato:

\section{- Page Post Video}

Se realizarán videos acerca de las situaciones planteadas a lo largo de toda la comunicación de la campaña, en las que el consumidor quisiera tomar una cerveza pero no puede. Estos videos están subidos tanto en la web como en el canal de Youtube y serán adaptados para que sean 
un preview para ser pauteados en este formato y al hacerles click podrás ver el video completo en el canal de Youtube.

\section{Formato de Facebook}

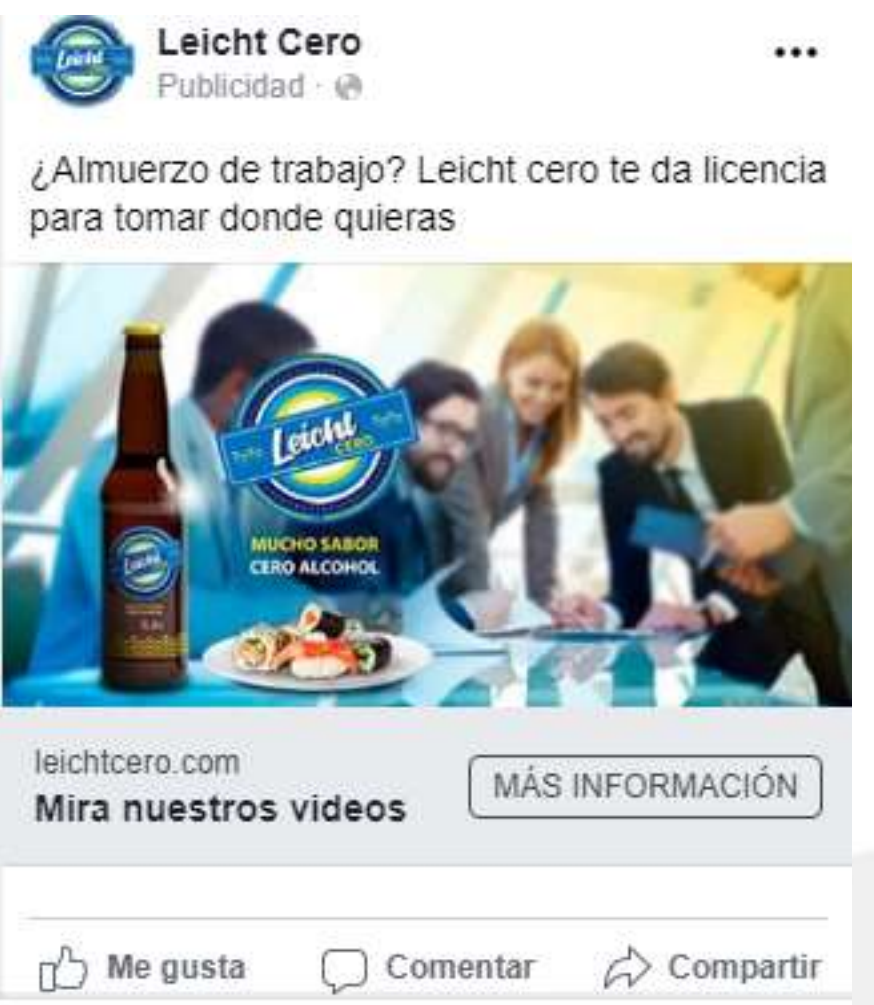

\section{Formato de Instagram}

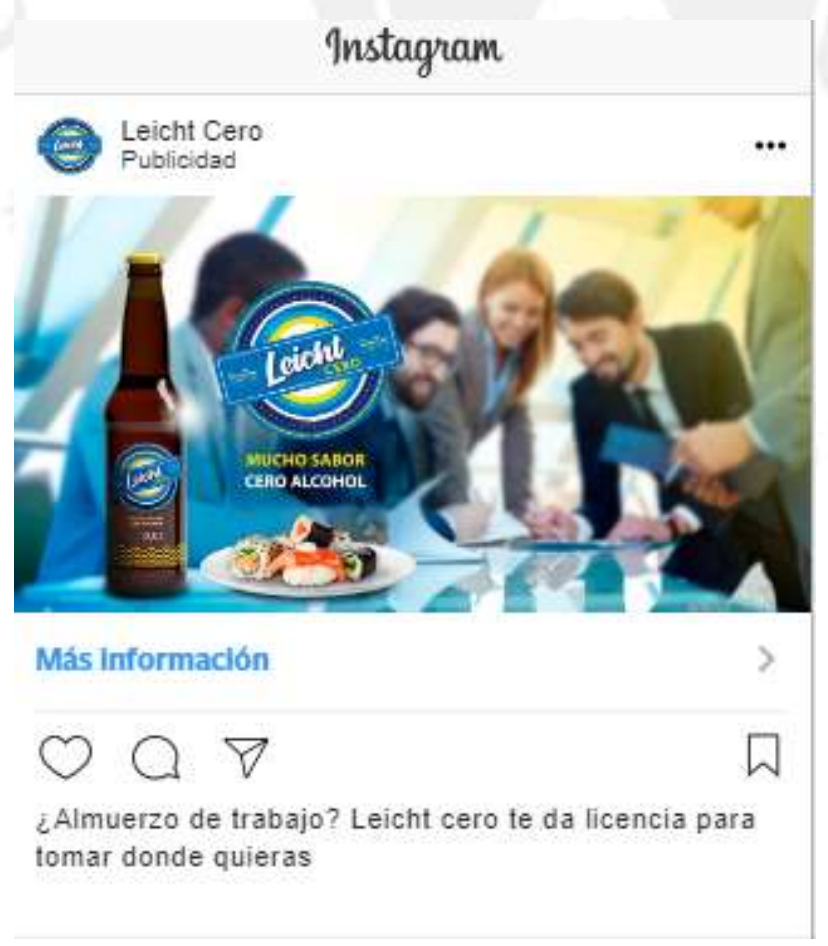




\section{Pauta Abierta:}

Se dirige a todas las personas que no han visitado la página web o que no conozcan la marca, será segmentado por intereses y estilos de vida, y tiene el objetivo de generar awareness acerca de la marca, su personalidad y sus beneficios.

\section{Formato de Facebook}

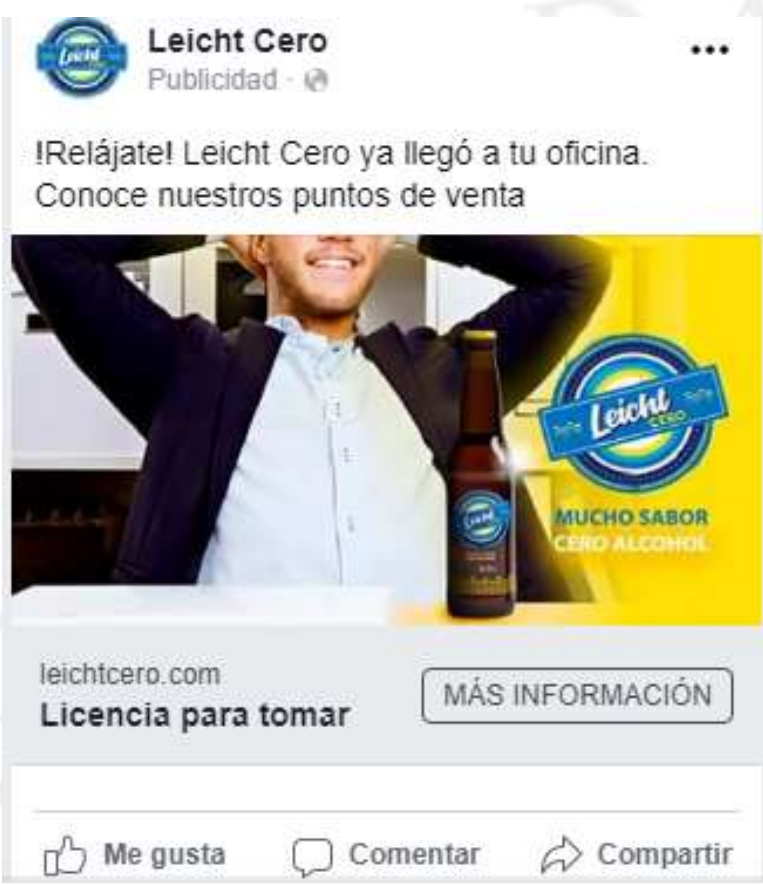

\section{Formato de Instagram}

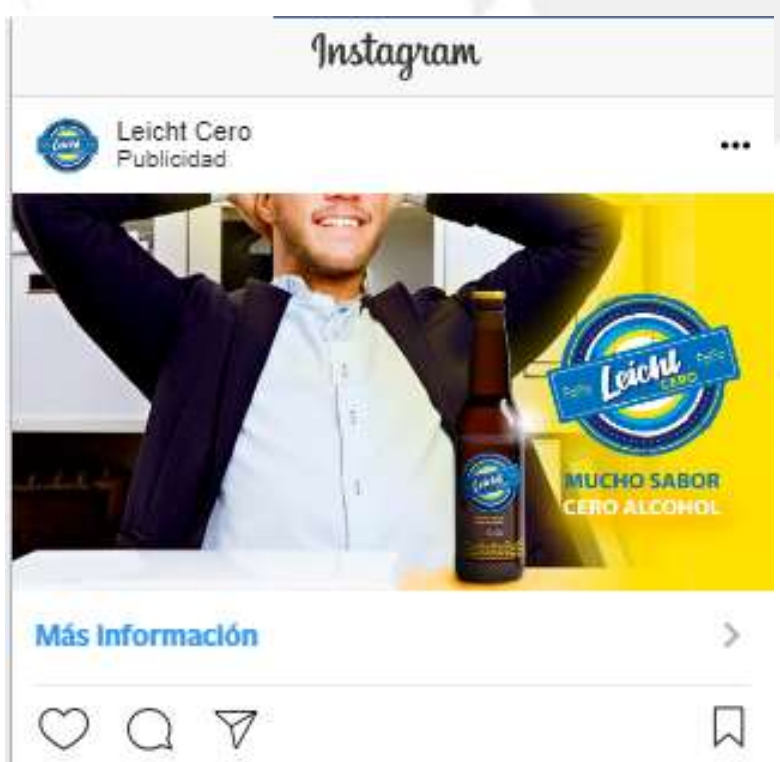

IRelájate! Leicht Cero ya llegó a tu oficina. Conoce

nuestros puntos de venta 


\subsubsection{Display}

Se insertarán anuncios en la la Red Display de google ya que nos permitirá aparecer en varios sitios webs de su red, teniendo en cuenta que Google tiene acuerdos con más de dos millones de sitios web, por lo que nos dejará impactar en una mayor cantidad de personas.

Para ello, produciremos un formato estático de las vallas de la etapa de lanzamiento. Se procederá a comprar o pujar por las palabras que más nos convengan para generar las pautas y que realmente nuestro search cumpla su función.

El motivo de las vallas será el mismo que se usó para la pauta en redes y para las vallas publicitarias.

\section{Implementación de Anuncio en Red de Display:}

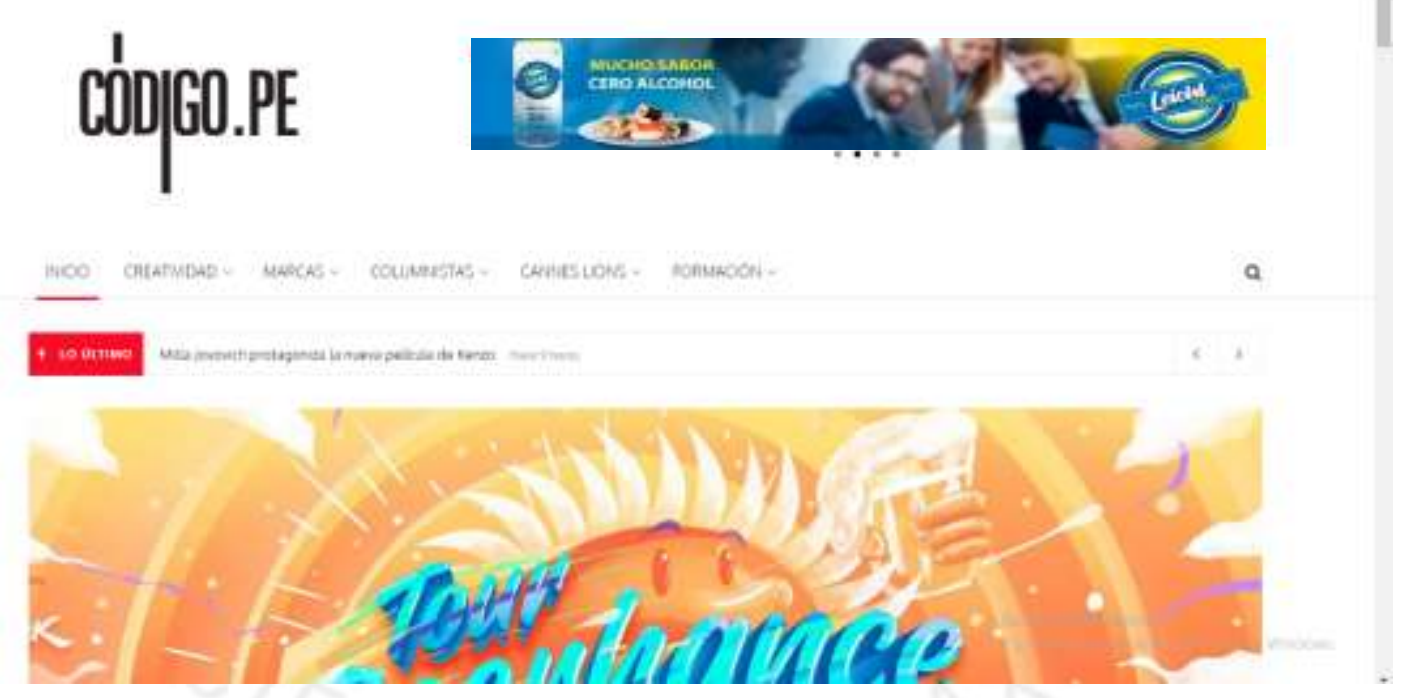

\subsubsection{Search}

Se comprará pauta en Google Search para tener visibilidad en buscadores y por ende tener mayor alcance entre las personas que busquen nuestras palabras claves compradas. Entre estas keywords se encuentran: cerveza sin alcohol, mucho sabor, cero alcohol, entre otros. 
Se presentan tres ejemplos de cómo se visualizarán los anuncios en buscadores cuando los usuarios busquen las palabras claves. Los reales deberían tener extensiones o botones para hacer más atractivo al anuncio.

\section{Licencia para tomar - Cerveza Leicht Cero \\ Anuncio www.leichtcero.com \\ Mucho sabor, cero alcohol. ¡Conoce nuestros puntos de venta!}

\section{Cerveza sin alcohol - Leicht Cero}

Anuncio www.leichtcero.com

Te da licencia para tomar cuando quieras. !Conoce nuestros puntos de venta!

\section{Mucho sabor, cero alcohol - Leicht Cero}

Anuncio www.leichtcero.com

\section{Cerveza que te da licencia para tomar siempre. \\ Conoce nuestros puntos de venta}

\subsubsection{Anuncio en Publimetro}

Como se busca introducir un producto nuevo al mercado, se necesita tener gran alcance. Por ello, se eligió este diario que es afín al target y es repartido gratuitamente en los principales puntos de Lima Moderna. Se comprará un anuncio que estará ubicado en la franja lateral de la portada del diario, para que sea más visible ante los usuarios.

\subsubsection{Spot de Televisión}

A pesar de que se ha dicho mucho sobre la disminución del consumo de televisión entre los jóvenes, sigue siendo el medio con mayor alcance masivo y según el perfil de adultos jóvenes de Ipsos, es el principal medio de entretenimiento cuando llegan a casa. (Ipsos,2018) 
Además, según un artículo del diario Gestión, "Podríamos pensar que los jóvenes pasan más tiempo usando Internet que la televisión tradicional, pero, según datos de Nielsen, tampoco es correcto. Los jóvenes de entre 18 y 24 años pasan alrededor de 87 horas y 10 minutos al mes ante la televisión, mientras que transcurren 20 horas y 42 minutos en computadora." (Gestión, 2016)

Por ello, se aprovechará esta oportunidad para impactar a un gran número de personas que pertenezcan a nuestro target. El spot será transmitido en canales de cable ya que según los análisis de canales nacionales e internacionales, nuestro target ve más televisón por cable que de señal abierta. Por ende, se escogió los canales Fox y Sony para transmitir la publicidad con el objetivo de impactar a nuestro público objetivo.

\section{Propuesta de Storyline:}

Un miércoles cualquiera a la hora de almuerzo está un jefe sentado en un restaurante, llega su equipo y el jefe pide Leicht Cero para todos. Horas más tarde se les puede ver en la oficina trabajando alegremente y con normalidad.

El spot hace referencia a las situaciones planteadas anteriormente en las que el consumidor no puede tomar una cerveza por sus obligaciones. Pero ahora con Leicht Cero si puede porque tiene licencia para tomar en donde quiera. Para transmitir la personalidad divertida y desenfadada de la marca, se tomó como referencia el estilo del director de cine británico Guy Ritchie para la presentación de los personajes. Las películas de Guy Ritchie se caracterizan por sus tomas en donde la imagen se detiene y luego se hace un acercamiento rápido a los personajes, haciendo más dinámica y divertidas la secuencia de tomas.

Restaurante. Jefe sentado con la cerveza en la mesa (Leicht Cero). Aparece en letras blancas "Miércoles 1:00pm"

Plano General

Se enfoca al jefe sentado en la mesa solo

Plano Entero 
Se hace un efecto de zoom y se congela el cuadro con un filtro azul cuando el jefe toma la cerveza. Aparecen en letras grandes y blancas "El jefe"

Entran al restaurant dos chicas y un chico (también con ropa de trabajo) Plano General

Otra vez el efecto de zoom a los tres chicos y se congela el cuadro con el filtro azul. Aparecen sus nombres en las mismas letras blancas, debajo aparece la frase "El equipo del jefe"

Jefe sentado en la mesa. Los ve, sonríe y llama al mozo Primer plano

Le hace una seña con la mano. Plano detalle

Los cuatro sentados en la mesa Plano general

Mozo trae cuatro cervezas Leicht Cero

Plano Medio

Los cuatro colaboradores tomando la cerveza. Ocurre el mismo efecto de zoom y se congela la pantalla con el filtro azul. Aparecen letras blancas "Leicht Cero te da licencia para tomar en almuerzos de trabajo"

Se "descongela la pantalla y se ve a los cuatro, cada uno con la cerveza, con cara de relajo

Logo con el slogan "Mucho sabor, cero alcohol"

Se ve a los tres trabajadores y a su jefe sentados en reunión de trabajo cada uno con sus laptops. Y uno de ellos dice: "Jefe, ¿mañana almorzamos de nuevo?

Plano general 


\subsubsection{Publicidad en Apps}

Debido a que se busca comunicar la nueva marca y generar posicionamiento, se eligió dos apps muy utilizadas por el target, que nos generará muchas impresiones y ayudará a la recordación de la marca. Se invertirá en ambas apps durante los 3 meses de la etapa de lanzamiento.

\subsubsection{Waze}

Para publicitar anuncios en waze, se eligió el formato "Zero speedTakeover", que te permite poner anuncios de la marca y te ofrece la ruta de camino al punto de venta cada vez que el conductor detenga el carro. Se permanecerá con esta publicidad durante los 3 meses de la etapa de lanzamiento, lo que es una gran oportunidad para dar a conocer Leicht Cero.

\section{Ejemplo de Publicidad}

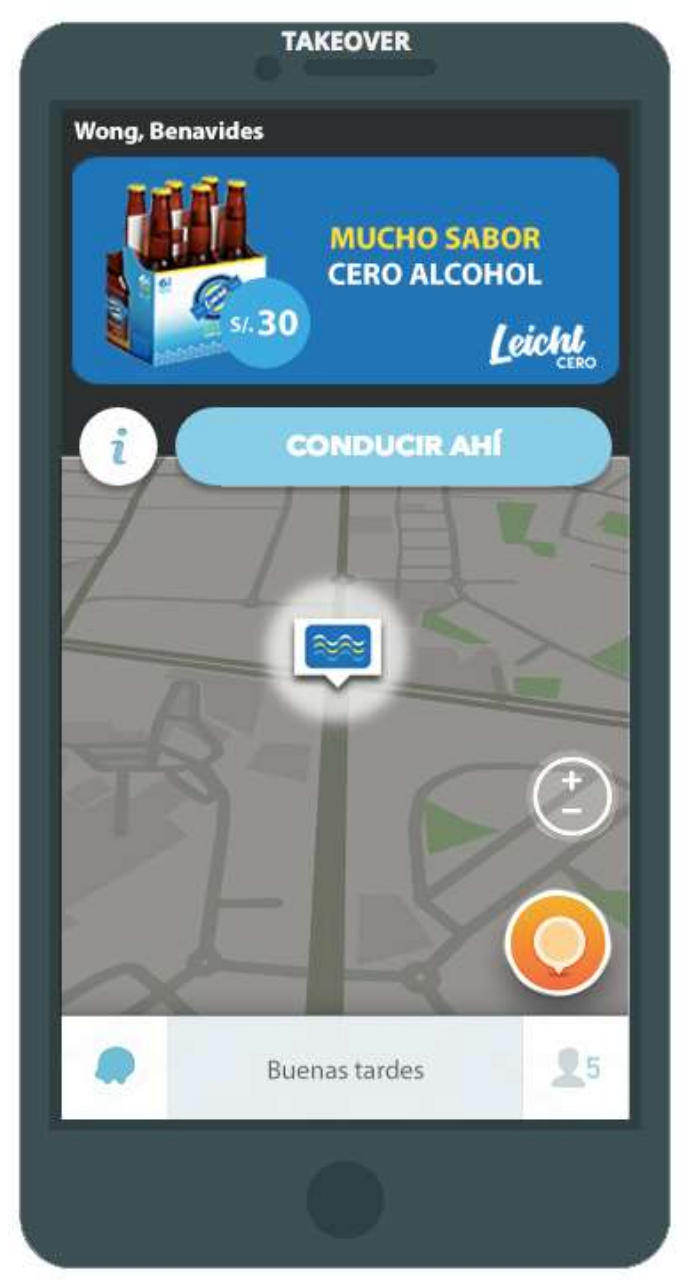




\subsubsection{Spotify}

Para los anuncios de Spotify se utilizará el formato de Audio que nos permitirá colocar nuestra cuña de audio entre las canciones de sesiones gratis activas. Además, nos permitirá tener una pieza gráfica complementaria de la marca que irá ubicada en el lugar donde van las portadas de los álbumes, que es re dirigible a la página web de Leciht Cero.

\subsubsection{Radio}

Se eligió utilizar este medio porque es el que más penetración tiene en nuestro país. Asimismo, la radio nos ayuda a generar mayor recordación de marca, gracias a que nos da frecuencia. De acuerdo a nuestro público objetivo, se seleccionaron las siguientes radios para poner nuestra pauta: Planeta, Studio 92 y Radio Disney, que es bastante afín al oyente joven peruano.

Se adaptará el guion de Televisión a este medio para que ambas publicidades transmitan el mismo mensaje y estén alineadas, generando consistencia en la campaña. La cuña de audio tendrá una duración de 20 segundos.

\section{Guión:}

\begin{tabular}{|l|l|l|}
\hline Voces y Locuciones & Música & Efectos \\
\hline $\begin{array}{l}\text { Jefe, ya tengo listo el reporte para la } \\
\text { reunion en unos minutos }\end{array}$ & & \\
\hline Excelente Juan, salud por eso & & \\
\hline & & $\begin{array}{l}\text { Sonido de choque de } \\
\text { botellas para brindar. }\end{array}$ \\
\hline & & $\begin{array}{l}\text { Sonido de alguien } \\
\text { tomando algo }\end{array}$ \\
\hline $\begin{array}{l}\text { Leicht Cero, la cerveza sin alcohol } \\
\text { que te da licencia para tomar hasta en } \\
\text { la oficina }\end{array}$ & \multirow{2}{*}{ Música de fondo } & \\
\hline $\begin{array}{l}\text { Leicht Cero. Mucho sabor, cero } \\
\text { alcohol }\end{array}$ & & \\
\hline
\end{tabular}




\subsubsection{BTL}

Un aspecto trascendental de esta campaña es que la gente pruebe el producto, debido a que para tener credibilidad y que realmente pueda ser vista como opción de consumo, los consumidores deben comprobar su buen sabor igual al de una cerveza convencional. Para ello, realizaremos tres acciones:

\subsubsection{Degustaciones:}

Se harán degustaciones los sábados y domingos durante 3 meses, que es lo que dura la etapa de lanzamiento, en los puntos de venta de los distritos de Lima Moderna como San Isidro, Miraflores, San Borja, Surco y La Molina. Teniendo en cuenta que el producto se distribuirá en supermercados Wong, Vivanda, Plaza Vea y Tottus, tiendas Listo, Repshop, Viva y Tambo; se realizarán las degustaciones en cuatro puntos de venta por fin de semana (dos supermercados y dos tiendas), para que el producto pueda estar presente en todos los lugares de venta.

\subsubsection{Activaciones en Oficinas:}

Se hará alianzas estratégicas para visitar ocho empresas a lo largo de la campaña de lanzamiento, que nos permitan entrar en sus cafeterías a la hora de almuerzo y repartir las cervezas sin alcohol a sus colaboradores. También se les repartirá merchandising como pockets, que nos permitirá ganar recordación de marca. Además, los influencers que participaron en la etapa de intriga, nos ayudarán yendo a estas activaciones y haciendo stories en sus cuentas de instagram y facebook para generar mayor impacto.

Dentro de las empresas que escogimos se encuentran Supermercados Peruanos, interbank, Entel, Saga Falabella, Jhonson \& Jhonson, Scotiabank, Tottus y Banco Cencosud; ya que se encuentran en la lista de Great Place To Work 2018 para Millenials. En el reporte de la página web de Great Place To Work se afirma que "Los mejores lugares para trabajar para millennials se caracterizan por ser organizaciones en dónde se implementan prácticas de capacitación y desarrollo, se hacen reconocimientos especiales y se brinda estabilidad laboral. Asimismo, cuentan con una población millennial que está muy orgullosa de pertenecer a su organización y está dispuesta a dar un esfuerzo extra, 17 veces más, que en el resto de organizaciones, como consecuencia existe una mayor capacidad de retención de esta población por parte de las empresas." (Great Place To Work, 2018). Es por ello que se entiende que estas empresas tienen una cantidad importante de nuestro target 
y se preocupan por la satisfacción de sus colaboradores, por lo que si estarían dispuestos a aceptar que Leicth Cero pueda ser repartida en sus comedores, ya que promueve el consumo responsable de cerveza.

\subsubsection{Sampling Publimetro}

Además de estar presente en la portada del diario, se repartirá latas de Leicht cero en puntos estratégicos de los distritos de Lima Moderna: Surco, La molina, San isidro, Miraflores, San Borja. Estos son algunos de los puntos de reparto:

- Cruce de la Avenida Velasco Astete con Avenida Primavera.

- República de Panamá con Canaval y Moreyra

- Avenida La Molina

- Avenida Javier Prado

- Avenida Caminos del Inca

Asimismo, las personas que repartan los diarios y las latas, vestirán un polo con el logo de la marca y mensajes como "Leicht Cero te da licencia para tomar en el trabajo", "Mucho sabor, cero alcohol".

En las tres activaciones, se repartirán volantes que informarán acerca del concurso e invitarán a los consumidores, a través de un código $\mathrm{QR}$, a entrar en la página web y dejar sus datos, además de visitar la página y conocer los beneficios de la marca. 


\section{REFERENCIAS}

- Redacción. (11 de mayo de 2018). Las bebidas no alcohólicas más vendidas en el Perú. El Comercio.

- Redacción. (14 de julio de 2017). El 78\% de los consumidores trata de cuidar su salud. El Comercio.

- Redacción. (02 de noviembre de 2016). Creadores de cerveza 'sin'y aromáticas. Diario de Valladolid

- Redacción. (30 de enero de 2017). Otra cerveza, por favor... pero sin alcohol. La Razón.

- Great Place to Work (2018). Los Mejores para Trabajar para Millenials. (2). Recuperado de https://www.greatplacetowork.com.pe/images/lists/ReporteMillennials-2018.pdf

- Redacción. (06 de julio de 2016). Análisis: Los mitos de la televisión abierta. Gestión.

- Costa, J. (2014). La Imagen de Marca. Barcelona: Paidos.

- Villafaña, G. (2007). Educación Visual: Conocimientos Básicos para el Diseño. México: Trillas 


\begin{abstract}
ANEXOS
Se realizó un sondeo para conocer las opiniones del target al que se dirigió la campaña, con respecto a sus hábitos de consumo cervecero y el producto que se busca introducir al mercado, la cerveza sin alcohol. La muestra fue de 36 hombres y mujeres de 18 a 35 años de NSE AB. Se debe considerar que se dejaron algunas preguntas abiertas, ya que no se quería limitar las respuestas de los encuestados, para poder conocer sus verdaderas percepciones. Se obtuvieron las siguientes respuestas:

- ¿Qué factor te parece más importante al momento de elegir una cerveza?

El 75\% de los encuestados afirmaron que el sabor era el factor más importante, seguido por la marca con un $11 \%$, la calidad con un $3 \%$ y el precio con un $5 \%$.

- ¿En qué occasion tomas cerveza?

Todos los encuestados contestarón que en reunions sociales o con amigos, son las ocasiones en las que más toman cerveza.

- ¿Con qué frecuencia consume cerveza?

El 30\% toma una vez a la semana, seguido del $25 \%$ que toma dos veces al mes, el $16 \%$ que toma dos veces por semana, el $13 \%$ que toma 1 vez al mes, el $8 \%$ una vez cada 6 meses y el $2 \%$ que toma a diario.

- ¿En qué occasion has querido tomar una cerveza y no has podido? Las respuestas más usadas fueron: Cuando tomaba medicamentos, después de las 11pm, días muy ocupados de estudios o trabajo, en el trabajo.

- ¿Qué te hace preferir una bebida alcohólica a una bebida sin alcohol? Las respuestas se dividieron entre "la ocasión que me permite relajarme", el sabor y los efectos.

- ¿Sabías que eiste la cerveza sin alcohol en el Mercado peruano?

El 69\% no conocía la cerveza.

- Si respondiste si, ¿alguna vez has consumido?

El $85 \%$ contestó que no la ha probado.
\end{abstract}


- Si respondiste si, ¿por qué la consumiste?

Teniendo en cuenta que solo tres personas contestaron esta pregunta, solo una persona aseguró que probó este tipo de cerveza para probar. El resto de personas afirmaron que fue por error 0 probaron Quara cuando fueron menores de edad.

- ¿En qué ocasiones tomarías una cerveza sin alcohol?

La gran mayoría contest que bebería este tipo de cerveza solo en situaciones en las que no puedan consumer alcohol. Por otro lado, siete personas afirmaron que no la consumirían. 